\title{
PROCESOS PARTICIPATIVOS COMO BASE PARA EL CONTENIDO Y DESARROLLO DE LA APLICACIÓN MÓVIL DE REALIDAD AUMENTADA: AMÓN_RA, COSTA RICA
}

Revista Trama

Volumen 8 , número 2

Julio - Diciembre 2019

Páginas 43-94

ISSN: 1659-343X

https://revistas.tec.ac.cr/trama
Participatory Processes As A Basis For The Content And Development Of The Mobile Application Of Augmented Reality: Amón_RA, Costa Rica

Jose Pablo Bulgarelli Bolaños ${ }^{1}$ María del Carmen Valverde-Solano ${ }^{2}$

Fecha de recepción: 22 de setiembre de 2019 Fecha de aprobación: 1 de diciembre de 2019

Bulgarelli, J. y Valverde, M. (2019). Procesos participativos como base para el contenido y desarrollo de la aplicación móvil de realidad aumentada: Amón_RA, Costa Rica. Trama, Revista de ciencias sociales y humanidades, Volumen 8, (2), págs. 43-94.

1. Arquitecto, Docente - investigador. Máster en Gerencia de Proyectos. Instituto Tecnológico de Costa Rica, Escuela de Arquitectura y Urbanismo, Campus Tecnológico Local San José. San José, Costa Rica. Correo electrónico: jpbulgarelli@tec.ac.cr. ORCID iD: https://orcid.org/0000-0001-5476-6544

2. Diseñadora Industrial, Docente - investigadora. Máster en Gerencia de Proyectos. Instituto Tecnológico de Costa Rica, Escuela de Diseño Industrial, Campus Tecnológico Central Cartago. Cartago, Costa Rica. Correo electrónico: mcvalverde@tec.ac.cr. ORCID iD: https://orcid.org/0000-0002-2203-8128 


\section{Resumen}

Este artículo aborda el tema de la participación de actores clave vinculados al proyecto de investigación Amón_RA: Implementación de la realidad aumentada como herramienta para la puesta en valor y difusión del paisaje urbano histórico de barrio Amón, en San José, Costa Rica. El producto del proyecto será una aplicación móvil, con la que el visitante de barrio Amón pueda obtener, en tiempo real, información sobre las diferentes capas del paisaje urbano histórico que le rodea, permitiéndole generar un criterio del valor natural, histórico, cultural y social de este sector urbano. La entidad financiadora del proyecto fue la Vicerrectoría de Investigación y Extensión del Instituto Tecnológico de Costa Rica (TEC).

El artículo responde a la pregunta, cómo los procesos participativos pueden ser un medio tanto para validar como descubrir información de un barrio y la estratificación de sus diferentes componentes urbanos a través del tiempo, con el propósito de plasmar los datos en contenido para una aplicación móvil de realidad aumentada. El tipo de investigación es cualitativa, con un enfoque constructivista donde las personas relacionadas con barrio Amón participaron como fuente primaria de información, lo que le permitió al equipo investigador descubrir datos cualitativamente significativos para poner en valor el paisaje urbano histórico.

Los procesos participativos brindaron el medio para un mayor entendimiento de los significados y experiencias de las personas que habitan o permanecen en el barrio; así como para validar la información encontrada en fuentes formales. Como principal conclusión es que por el valor de la información cualitativa de parte de los agentes sociales, tales como vivencias, anécdotas y secretos como parte del contenido en la aplicación móvil, esta toma un aspecto más cercano para los usuarios. Los procesos participativos en torno a la aplicación fueron un medio para reunir y documentar información no formal que pertenece a la intimidad de las familias vecinas, que se encuentran en un momento histórico donde buscan perpetuar la memoria e identidad de barrio Amón.

Palabras clave: patrimonio, agentes sociales, paisaje urbano histórico.

3. El proyecto toma su nombre uniendo el antropónimo del lugar en estudio, en este caso de barrio Amón, con la sigla RA que, en la literatura, hace referencia al concepto de Realidad Aumentada. 


\section{Abstract}

This article deals with the participation of key actors linked to the research project Amón_RA : Implementation of augmented reality as a tool for the enhancement and promotion of the historic urban landscape of the Amón neighborhood in San José, Costa Rica. The product of the project will be a mobile application, with which the visitor of neighborhood Amón can obtain, in real time, information about the different layers of the historical urban landscape that surrounds him, allowing him to generate a criterion of the natural, historical, cultural and social value of this urban sector. The funding entity of the project was the Vice-Rectory of Research and Extension of the Costa Rica Institute of Technology (TEC).

The article answers the question, how participatory processes can be a means to both validate and discover information about a neighborhood and the stratification of its different urban components over time, with the purpose of translating the data into content for a mobile application of augmented reality. The type of research is qualitative, with a constructivist approach where people related to Barrio Amón participated as a primary source of information, which allowed the research team to discover qualitatively significant data to value the historic urban landscape.

Participatory processes provided the means for a greater understanding of the meanings and experiences of the people who live or stay in the neighborhood, as well as to validate the information found in formal sources. The main conclusion is that for the value of the qualitative information provided by social agents, such as experiences, anecdotes and secrets as part of the content in the mobile application, this takes a closer look for users. The participative processes around the application were a means to gather and document non-formal information that belongs to the intimacy of the neighboring families, who are in a historical moment where they seek to perpetuate the memory and identity of Barrio Amón.

Keywords: heritage, social agents, historic urban landscape.

4. The project takes its name by uniting the anthroponomy of the place under study, in this case the neighbourhood of Amón, with the acronym RA which, in literature, refers to the concept of Augmented Reality in Spanish. 


\section{INTRODUCCIÓN}

Gran parte del éxito de los esfuerzos temporales, o trabajos que se ejecutan en períodos definidos, que se llevan a cabo para crear un producto, un servicio o un resultado único ${ }^{5}$, radica en la participación de los interesados en las diferentes fases del ciclo de vida del proyecto. Según sean los objetivos, las investigaciones requieren, al igual que otros tipos de proyectos, de legitimación y el involucramiento de los agentes sociales. El proyecto de investigación Amón_RA tuvo como objetivo general implementar la realidad aumentada (RA) como herramienta para la puesta en valor y difusión del Paisaje Urbano Histórico de Barrio Amón (PUHBA). Este objetivo se pretendió alcanzar mediante el desarrollo de una aplicación móvil de RA que le permite al usuario acceder, en tiempo real, a una serie de información relacionada a los valores naturales, históricos, culturales, sociales e identitarios del barrio Amón_RA. Se visualiza como un hito en la evolución de aplicaciones móviles en Costa Rica para la puesta en valor y difusión del patrimonio, contemplando la percepción e interacción del usuario con el mundo real.

En este artículo se abordan los resultados del segundo objetivo específico ${ }^{6}$ con el cual se pretendió, a partir de procesos participativos con agentes sociales involucrados en el proyecto, validar la información base del PUHBA. Cabe destacar que estos agentes no sólo validaron contenidos formales, si no que aportaron información valiosa tanto para el desarrollo técnico de la aplicación, como datos que suelen quedar en la vida privada de los actores sociales o no registrados en fuentes oficiales que, por su valor en la formación de la identidad del barrio, fueron incorporados en la aplicación. El proyecto fue liderado por la Escuela de Arquitectura y Urbanismo (EAU), en conjunto con las Escuelas de Diseño Industrial (DI) e Ingeniería en Computación (IC) del Instituto Tecnológico de Costa Rica (TEC). Estas tres unidades académicas aportaron el recurso humano que conformó el equipo investigador ${ }^{7}$; además se vincularon con el Departamento de Geografía de la Universidad Autónoma de

5. Definición de proyecto según la Guía $\mathrm{PMBOK}^{\circledR}$ 6ta edición.

6. Los objetivos específicos del proyecto Amón_RA son:

1. Identificar los elementos que componen el paisaje urbano histórico de barrio Amón (PUHBA).

2. Validar la información de base del PUHBA con la participación de los agentes sociales involucrados en el proyecto.

3. Elaborar un prototipo de aplicación móvil para realidad aumentada en el PUHBA.

4. Diseñar el sofware y su interfase para el procesamiento de la información bajo la utilización de la realidad aumentada.

5. Desarrollar la aplicación móvil de realidad aumentada (Amón_RA).

6. Evaluar la utilización de la aplicación móvil (Amón_RA) con miras a su mejoramiento y posible empleo en otros contextos. 
Madrid (UAM), mediante la participación de dos expertos ${ }^{8}$ en turismo cultural. También contó con el apoyo del Centro de Investigación y Conservación del Patrimonio Cultural (CICPC) del Ministerio de Cultura y Juventud (MCJ) y la Municipalidad de San José (MSJ). Además, Amón_ RA contó con la participación de estudiantes de las tres escuelas con las figuras de asistencia especial y práctica de vinculación profesional. Por otro lado, el proyecto fue apoyado durante los primeros dos años por la Dirección de Posgrado con la vinculación de un estudiante de la Maestría en Gerencia de Proyectos del TEC, por medio de la beca asistente especial de posgrado.

Para comprender el ámbito de trabajo de Amón_RA, es necesario conceptualizar lo que se entiende por Paisaje Urbano Histórico (PUH). La recomendación de la UNESCO de 2011 define al PUH como aquella zona urbana resultante de una estratificación histórica de valores y atributos culturales y naturales, lo que trasciende la noción de "conjunto" o "centro histórico" para abarcar el contexto urbano general y su entorno geográfico (UNESCO, 2011). En este sentido, el proyecto comprende al PUHBA como aquella zona urbana conocida administrativamente con el nombre de barrio Amón siendo esta uno de los primeros ensanches al norte de la ciudad de San José, Costa Rica. Esta zona se encuentra integrada a su contexto natural y ha sido construida por las comunidades que la han habitado a través del tiempo. En este concepto del PUHBA se mezcla lo antiguo con lo contemporáneo y refleja huellas tangibles como: edificaciones, espacios públicos, elementos patrimoniales y entornos naturales; así como intangibles: gastronomía y todo tipo de expresiones artísticas.

Barrio Amón se encuentra al norte de la ciudad de San José, que se construyó físicamente en lo que fue un cafetal a finales del siglo XIX y principios del siglo XX, entre avenida 7 y el río Torres, limitando al oeste con calle 0 y al este con lo que fue la continuación de calle 9; siendo uno de los primeros barrios residenciales de la ciudad capital. La Imagen 01 muestra el proyecto planteado por Amón Fasileau Duplantier, en 1892, donde se proyecta el ensanche de la ciudad de San José en terrenos que, para ese momento, eran utilizados en el cultivo de café.

7. Escuela de Arquitectura y Urbanismo: Dr. Arq. David Porras Alfaro (Coordinador), Dra. Arq. Kenia García Baltodano, Mstr. Arq. Tomás Martínez Baldares, Mstr. Arq. Jose Pablo Bulgarelli Bolaños. Escuela de Diseño Industrial: Mstr. DI. María del Carmen Valverde Solano. Escuela de Ingeniería en Computación: Mstr. Ing. Esteban Arias Méndez (2018) y Mstr. Ing. Ericka Solano Fernández (2019).

8. Dr. Diego Barrado Timón y Dra. Carmen Hidalgo Girald. 


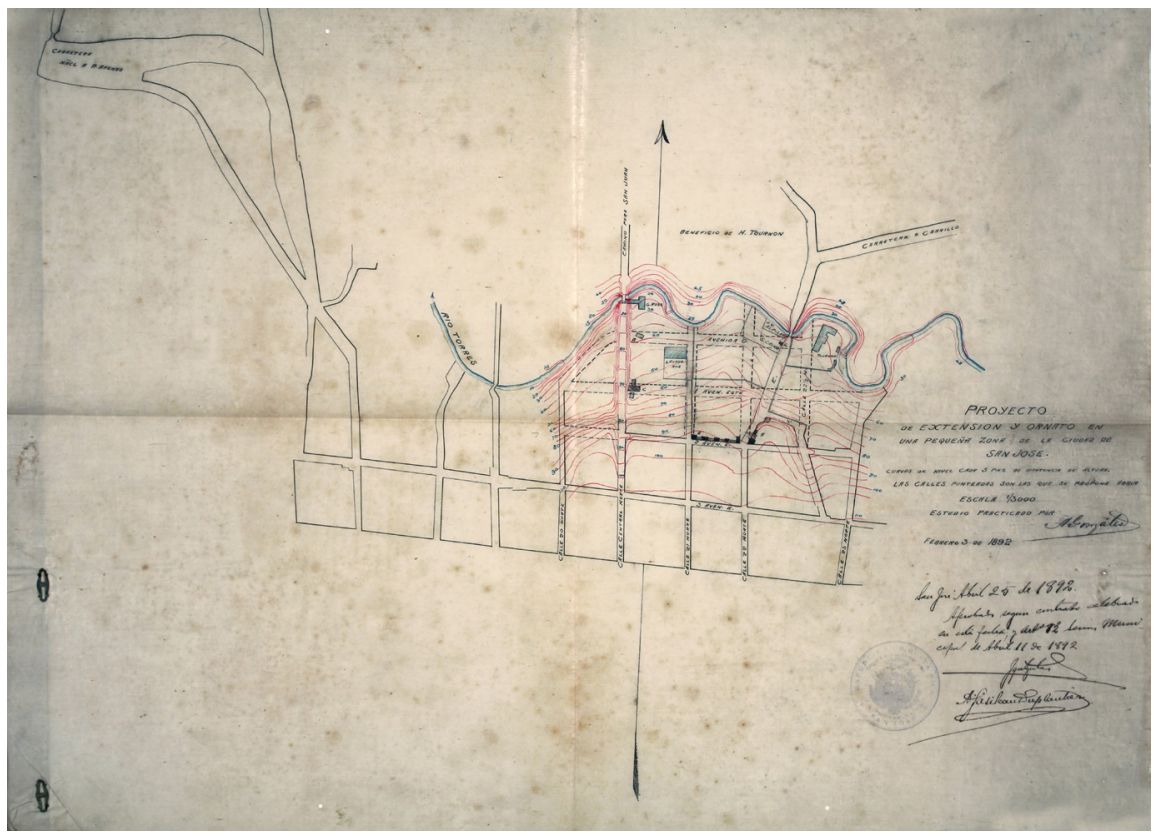

Imagen 01: propuesta de ensanche de la ciudad de San José, 1892. Firmada por Amón Fasileau Duplantier, influyente empresario francés radicado en Costa Rica del siglo XIX, quien tuvo a cargo el proyecto del ensanche de la ciudad de San José hacia el Norte.

Fuente: Expediente 35441, Registro Nacional de Costa Rica.

Este barrio es un referente josefino ya que cuenta con valores patrimoniales de tipo histórico, estético, simbólico y social. En más de cien años de constante evolución, mantiene parte de su carácter residencial, así como su tejido urbano, siendo un testigo vivo de la bonanza económica de las élites urbanas de la Costa Rica del siglo XX; es decir, de la producción cafetalera relacionada con el poder económico y político de ese momento histórico. En la Imagen 02 se señala la configuración urbana actual de barrio Amón. 


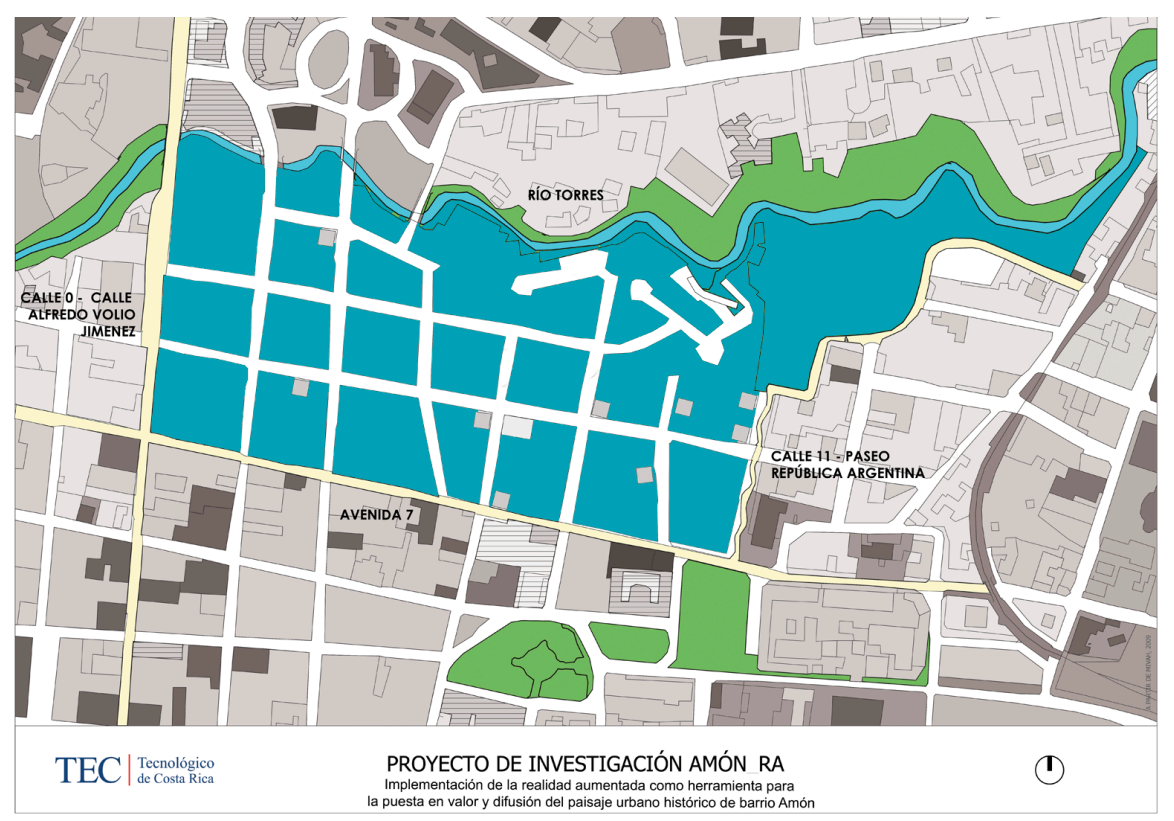

Imagen 02: plano de barrio Amón. Dicho sector de la ciudad de San José, Costa Rica, está conformado actualmente por las cuadras que se encuentran limitadas al Norte por el río Torres, al Sur por la avenida 7, al Este por calle 11 o paseo República Argentina y al Oeste por la calle 0 o calle Alfredo Volio Jiménez.

Fuente: Proyecto de investigación Amón_RA.

Actualmente es un espacio urbano en el que se encuentran varias instituciones estatales y privadas con importancia en la memoria de la ciudad, que posee atractivos naturales y turísticos, pero que en las últimas décadas ha sufrido procesos de despoblamiento y tercerización del uso de suelo. Estos cambios donde se insertan usos discordantes al residencial generaron procesos como el turismo sexual, la prostitución, indigencia y pérdida de bienes inmuebles con valor patrimonial. Es a partir de este contexto en que el proyecto Amón_RA, a partir del aún existente engranaje social, del interés por mejorar las condiciones físicas y reforzar la identidad barrial, pretende generar procesos que estimulen el interés por la zona mediante la tecnología y la innovación, con el fin de valorar los recursos del barrio y vincular acciones por parte los agentes sociales e interesados en la conservación de estos. 
Como se mencionó anteriormente, la aplicación prevista contempla el desarrollo de tecnología de RA. Johnson et al. (2013) define la Realidad Aumentada como una combinación de información digital en tiempo real y el campo de visión de una persona, a través de dispositivos móviles, que generan imágenes nuevas. Fombona, Pascual y Medeira (2012) indican que la tecnología de RA permite relacionar, en tiempo real, las imágenes y la posición geográfica del usuario con metadatos asociados y almacenados en un equipo móvil. De lo anterior se interpreta que el usuario de una aplicación móvil de RA puede, a través de esta, ampliar su experiencia más allá del contacto con los objetos y el contexto, pues le permite vincular información en diferentes formatos virtuales (imágenes, videos, audios, texto) a un elemento real (entorno físico, objeto, etc.). Dentro de los seis objetivos específicos del proyecto, se contempló el desarrollo del contenido de la aplicación móvil, así como la creación del App. Para ello fue necesario que un grupo de interesados claves, denominados "agentes sociales", validaran mediante procesos participativos y cualitativos la información base del PUHBA, así como la estructura de información propuesta para la aplicación. Esto último se consideró como el segundo objetivo de Amón_RA. La Guía del Project Management Institute (2017) define a los interesados como:

...un individuo, grupo u organización que puede afectar, verse afectado, o percibirse a sí mismo como afectado por una decisión, actividad o resultado del proyecto. Los interesados del proyecto pueden ser internos o externos al proyecto, pueden estar involucrados activamente, involucrados pasivamente, o desconocer el proyecto. Los interesados del proyecto pueden tener un impacto positivo o negativo, o recibir un impacto positivo o negativo del proyecto.

Ahora bien, Rebollo (2014) indica que una práctica participativa puede ser un momento específico en un proyecto o un proceso continuo, que se construye día a día y es el resultado de la interacción de los autores, que tienen precedentes y perspectivas de futuro. Por lo tanto, se puede definir un proceso participativo como una práctica donde los equipos de trabajo, con la interacción sistemática y ordenada de los autores o interesados del proyecto, alcanzan objetivos en común. A los equipos del proyecto les atañe cumplir con el trabajo que les fue encomendado y a los interesados les apremia resolver su situación problemática. En 
el caso de Amón_RA se diseñaron varios espacios de interacción con los interesados claves para el cumplimiento de los objetivos. Oliva, J. e Iso, A. (2014) señalan que las ventajas de estos procesos participativos es que legitiman el proyecto, así como la implicación y fomento de los interesados externos $y$, además, refuerzan el compromiso de los interesados internos por cumplir los objetivos. En el presente artículo se explica la metodología utilizada por el proyecto de investigación Amón_RA para identificar a los agentes sociales y ejecutar los procesos participativos ya mencionados; además, se exponen los resultados obtenidos. 


\section{METODOLOGÍA}

En barrio Amón el TEC cuenta con presencia física, académica y cultural mediante proyectosimpulsados por los diferentes departamentos y unidades académicas presentes en el Campus Tecnológico Local de San José. A partir de la información de estos proyectos se generó la base primaria de donde se pudieron identificar a los agentes sociales activos del barrio. Estos interesados externos del proyecto se agruparon en conjuntos según un análisis de poder ${ }^{9}$, interés ${ }^{10}$ e influencia ${ }^{11}$. De dicha clasificación surgieron cuatro grupos denominados: comunidad o vecinos, instituciones públicas, fundaciones y organizaciones de la sociedad civil, y por último se agrupa lo que el proyecto considera como "oferta cultural urbana", que la integran aquellas empresas que trabajan en este sector de la ciudad y que considera al patrimonio cultural dentro de su estrategia de negocio. El primer grupo estuvo integrado por la Asociación para la Conservación y Desarrollo de barrio de Amón y aquellas personas que residen en el barrio interesadas en temas relacionados al patrimonio cultural. El grupo de instituciones públicas lo integraron aquellas entidades del estado nacional y local con presencia física en el barrio, tales como el Instituto Nacional de Seguros (INS), el Instituto Nacional de Vivienda y Urbanismo, el Centro de Investigación y Conservación del Patrimonio Cultural (CICPC), el TEC y la MSJ. Por otro lado, barrio Amón es sede de organizaciones sin interés de lucro como la Fundación Pro-Zoológicos y de TEOR/ética, las cuales formaron parte del tercer grupo. Para involucrar a estos actores se planeó un proceso participativo que involucró la realización de talleres de investigación social de carácter cualitativo como grupos focales y cartografía social.

Los criterios de selección de las personas participantes fueron distintos, según el objetivo de cada taller en particular, ya que la información que se pretendía recoger fue diferente según las etapas del proyecto. El primer proceso denominado "Dibujando Amón", al que asistieron 123 personas, tenía como alcance conocer cuál es la imagen urbana y la percepción del paisaje de barrio Amón, para los diferentes actores sociales que tienen como punto de encuentro este territorio. Para lograr lo anterior, se aprovechó la convocatoria hecha en torno al Festival Amón Cultural del 4 de marzo del 2017, y se recolectó la información descrita anteriormente entre los participantes a la actividad. El criterio

9. Nivel de autoridad que posee un grupo sobre el proyecto. Project Management Institute (2017)

10. Nivel de inquietud sobre los resultados del proyecto que posee un grupo. Project Management Institute (2017)

11. Capacidad de influir en resultados del proyecto que posee un grupo. Project Management Institute (2017) 
de selección para participar en "Dibujando Amón", fue que la persona tuviese algún vínculo con el barrio; es decir, podía ser un residente, un usuario que, por motivos de trabajo o estudio, permanece un periodo determinado durante la semana en el barrio o, un visitante que al menos reconoce a barrio Amón dentro de la configuración urbana de la ciudad de San José.

El primer y segundo taller se ejecutaron en el segundo semestre del $2017^{12}$. Ambos procesos tenían un alcance en común; sin embargo, se ejecutaron en momentos distintos debido a que, al requerir de varias actividades para alcanzar los objetivos, se tuvo que dividir en dos talleres. El alcance fue validar la información que el equipo investigador ya había recolectado de fuentes secundarias, así como recolectar nueva información que no necesariamente está en los medios de registro formales. Por otro lado, también se pretendía conocer en estos talleres las necesidades y expectativas de los posibles usuarios de la aplicación móvil. Para lograr lo anterior, los criterios de selección de las personas participantes fueron:

1. Que esta persona conociera el alcance general del proyecto.

2. Que la persona tuviese un rol dentro de los procesos comunitarios del barrio.

3. Que la persona, por su rol social dentro del barrio, tuviese relación con algún acontecimiento o personaje y que, estuviese dispuesto a compartir información que le pareciera relevante para el proyecto.

El equipo de investigación pudo asegurarse que las personas a las que se invitó a participar en los talleres participativos cumplieran el primer criterio de selección ya que, previo a estos, organizó lo que se conoció como: jornadas de investigación. Estas jornadas fueron un ciclo de charlas de tres días ${ }^{13}$ para difundir trabajos previos o en proceso desarrollados por diferentes agentes sociales que tuvieran como ámbito de estudio barrio Amón, así como temáticas vinculadas a las dos líneas principales de investigación del proyecto ${ }^{14}$. De esta forma se levantó

12. Los talleres se ejecutaron el 26 de octubre y el 9 de noviembre del 2017, de 9:00 am a 11:00 am, horario identificado como el más apropiado para los agentes sociales.

13. 24 de agosto, 31 de agosto y 7 de setiembre del 2017, de 4:00 pm a 6:00 pm.

14. Revalorización urbana y patrimonial, y temas tecnológicos vinculados a la creación de aplicaciones móviles para realidad aumentada, turismo, cultura, geomarketing, temas urbanos, arquitectónicos, etc. 
una lista preliminar de las personas que participaron de una manera constante en las jornadas de investigación que, además de mostrar interés en el proyecto Amón_RA cumplieran con los dos últimos criterios de selección. Estos últimos criterios fueron identificados por el equipo a partir de las conversaciones informales durante los tiempos planificados entre charlas.

Al necesitar información puntual, el equipo de investigación realizó una identificación de los agentes sociales clave del barrio, mediante los tres criterios de selección. A estas personas se les envió un correo electrónico para invitarlos a los talleres y se les llamó para confirmar su participación. En total se invitaron a participar de ambos momentos a 35 personas, de las cuales confirmaron para el primer taller 27 personas ${ }^{15} y$ asistieron un total de 18 personas ${ }^{16}$. Para el segundo taller confirmaron 25 personas $^{17}$ y asistieron 16 personas $^{18}$ en total. En el caso del tercer taller ${ }^{19}$ los criterios de selección de los participantes fue que calzaran con el perfil de ser miembros de alguno de los cuatro grupos de clasificación de interesados externos, que conocieran del proyecto Amón_RA, y que supieran cómo utilizar un dispositivo móvil. Por el carácter del taller en donde se evalúa si los participantes logran realizar una meta de buscar un contenido específico en la maqueta funcional de la aplicación móvil, el número de personas convocadas fue de ocho $^{20}$ personas.

15. De las personas confirmadas para participar en el primer taller siete forman parte del grupo de vecinos, 13 del grupo de instituciones públicas, tres de fundaciones y organizaciones de la sociedad civil y cuatro del grupo de oferta urbana.

16. Al primer taller asistieron cuatro vecinos, 10 personas pertenecientes a instituciones públicas, tanto funcionarios de estas instituciones como estudiantes del Campus Tecnológico Local San José, dos personas pertenecientes al grupo de fundaciones y organizaciones de la sociedad civil, así como dos personas del grupo de oferta urbana.

17. De las personas confirmadas para participar en el segundo taller siete forman parte del grupo de vecinos, 11 del grupo de instituciones públicas, tres de fundaciones y organizaciones de la sociedad civil y cuatro del grupo de oferta urbana.

18. Al segundo taller asistieron cuatro vecinos, 11 persona pertenecientes a instituciones públicas, tanto funcionarios de estas instituciones como estudiantes del Campus Tecnológico Local San José y una persona perteneciente al grupo de fundaciones y organizaciones de la sociedad civil.

19. El tercer taller se realizó el 7 de diciembre del 2017.

20. Para el último taller se contó con la presencia de dos vecinos y seis funcionarios y estudiantes de las distintas instituciones del barrio. 
Por cada taller las actividades y su respectivo instrumento de aplicación fueron planificados a partir de cartas metodológicas. En ese documento se describió la propuesta, se indicó el día, la hora, el lugar y participantes; además se mencionó el vínculo que tiene el taller con el proyecto y sus objetivos. Por último, se describió específicamente cada una de las actividades, las tareas y quién las debía ejecutar, se especificó el instrumento y cómo se aplicaría; así mismo, los materiales necesarios para realizar la actividad. Los objetivos de los talleres participativos, cuyas actividades realizadas se describirán en los siguientes apartados, fueron:

1. Recopilar información vivencial, histórica, familiar, anecdótica que enriquezca los contenidos de la aplicación móvil.

2. Validar la información de la base de datos del proyecto por parte de los actores sociales de barrio Amón, en un proceso donde se contrasta los elementos del PUHBA con la visión propia de los agentes.

3. Validar los elementos de usabilidad, por medio de una serie de técnicas como definición de funcionalidades según las necesidades de los potenciales usuarios de la aplicación móvil, card sorting, y digital prototyping.

Las técnicas de los procesos participativos empleadas para alcanzar estos objetivos fueron planteadas por el equipo investigador, para brindar un espacio de diálogo con los interesados del proyecto. De esta forma se logró recopilar los aportes a nivel de vivencias, de reconocimiento y apropiación del barrio desde las diversas experiencias de los agentes sociales. Estas se tradujeron en contenidos para la aplicación móvil con un contexto propio, que, si bien tiene aspectos comunes con otras de las aplicaciones móviles para turismo, Amón_RA es un medio para vivir en tiempo real y a nivel tecnológico el paisaje urbano histórico, a través de la difusión de la memoria e identidad del barrio. 


\section{DIBUJANDO AMÓN}

El equipo de investigación ${ }^{21}$ aprovechó la oportunidad que ofrecía la versión 2017 del Festival Amón Cultural ${ }^{22}$, para ejecutar el proceso participativo "Dibujando Amón", con la intención de recabar información sobre la imagen urbana y la percepción del paisaje por medio de tres ejercicios simultáneos. Como se indicó, este taller se efectuó en el marco del festival. Si bien, dentro del plan de trabajo de Amón_RA, no estaba previsto realizar ninguna actividad participativa durante el primer semestre del primer año de ejecución, el equipo de investigación decidió aprovechar este espacio para interactuar por primera vez con residentes y visitantes del barrio, debido a la gran afluencia de personas durante ese día.

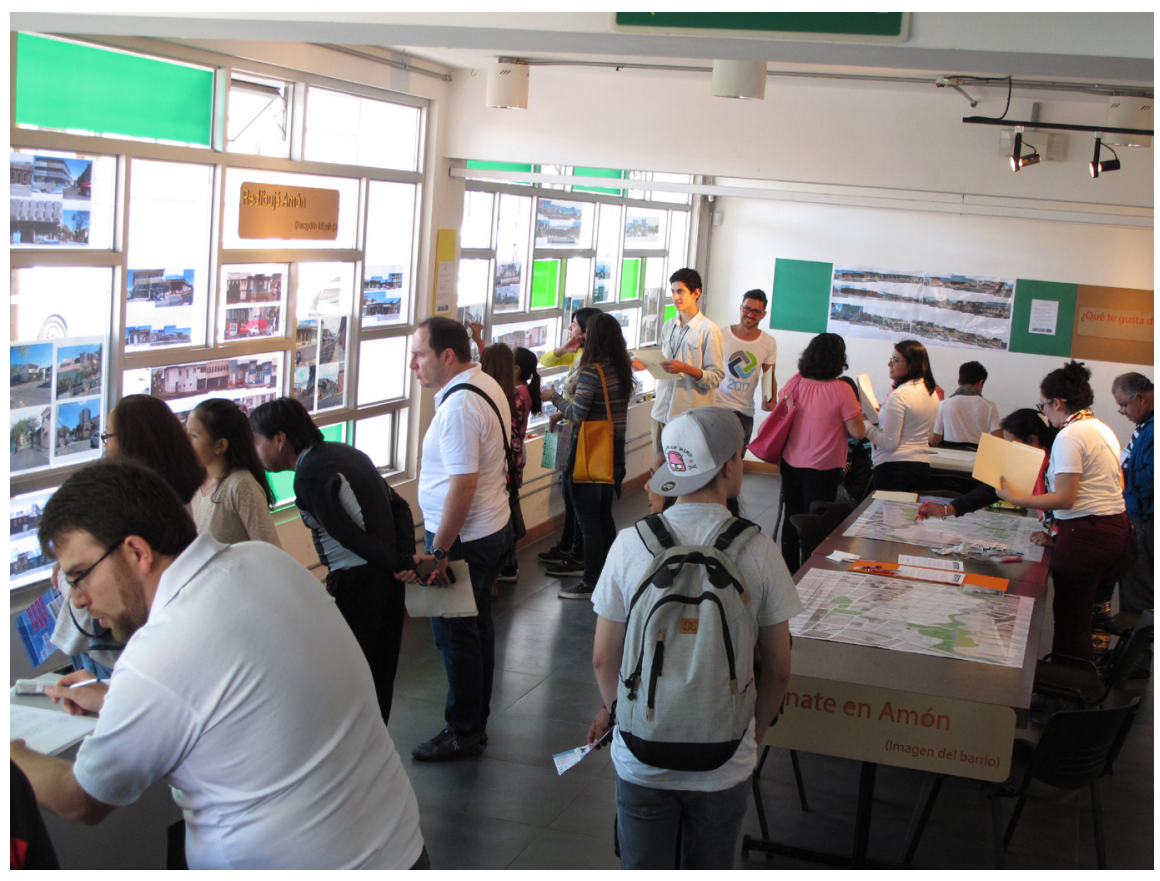

Imagen 03: vestíbulo de la Escuela de Arquitectura y Urbanismo del TEC durante el taller "Dibujando Amón". Dicho proceso participativo se ejecutó en torno al Festival Cultural Amón, el 4 de marzo de 2017.

Fuente: Proyecto de investigación Amón_RA.

21. El equipo de investigación del proyecto Amón_RA, fueron los responsables en el diseño y ejecución de los procesos participativos aquí descritos, este equipo estuvo compuesto durante el primer año del proyecto por: Dr. Arq. David Porras Alfaro (Coordinador), Dra. Arq. Kenia García Baltodano, Mstr. Arq. Tomás Martínez Baldares, Mstr. Arq. Jose Pablo Bulgarelli Bolaños, Mstr. DI. María del Carmen Valverde Solano y el Mstr. Ing. Esteban Arias Méndez. Los estudiantes que participaron en el trabajo concerniente a algún taller fueron: David Mena Marín, Deborah Valverde Soto, Diana Alvarado Poveda, Danny Oconotrillo Obando, Ismael Arias Zapata, Jacqueline Arias Flores, Silvia Jiménez Loaiza, Yendry Mora Cascante, Joseph Vargas González, Gloriana Vargas Castro, Gerald Cordero Arias, Angélica María Rodríguez Delgado y Joseph Salazar Acuña. 
22. Según los organizadores, el Festival Amón Cultural es una iniciativa gestada desde la Unidad de Cultura y Deporte del TEC en el Campus Tecnológico Local San José, con el apoyo de los vecinos, emprendimientos, comercios, instituciones y gestores locales. El Festival se realiza una vez al año desde el 2014 en el primer sábado de marzo y se concibe como una plataforma que, por medio de diferentes actividades ejecutadas en diferentes puntos comerciales, privados, institucionales y espacios públicos del barrio, permite la difusión y promoción de la vida artística y cultural de barrio Amón. El proyecto Amón_RA se vinculó como una actividad de la Escuela de Arquitectura y Urbanismo con una instalación dentro del vestíbulo del primer piso de su edificio ubicado en la esquina entre calle 5 y avenida 9 de la ciudad de San José, donde los visitantes del Festival podían, mediante actividades lúdicas, brindar información a la investigación.

En “Dibujando Amón” se plantearon los siguientes objetivos:

- Identificar los elementos que componen el PUHBA según la percepción de las personas que habitan barrio Amón y de los visitantes al evento "Amón Cultural" a través de la expresión gráfica libre.

- Valorizar los elementos que componen el PUHBA según la percepción de los participantes al evento "Amón Cultural" a través de la expresión gráfica guiada.

- Identificar la morfología o imagen de barrio Amón desde la perspectiva de quien lo habita y visita, a través de la elaboración de una cartografía social basada en los elementos de la imagen de la ciudad propuestos por Kevin Lynch (1998).

- Difundir conocimiento e información sobre barrio Amón por medio de los ejercicios desarrollados.

Para lograr estos objetivos se plantearon tres actividades específicas, las cuales se realizaron en el vestíbulo del primer nivel de la Escuela de Arquitectura y Urbanismo del TEC, en el Campus Tecnológico Local San José. Los participantes fueron residentes, usuarios y visitantes del barrio durante el festival, estudiantes voluntarios de Arquitectura y Urbanismo y el equipo investigador de Amón_RA. A continuación, se describen las actividades ejecutadas en el taller.

Dibujo libre: ¿Qué te gusta de Amón?

"Dibujo libre" estaba relacionado con el primer objetivo de Dibujando Amón. Consistió en preguntarle al visitante de la actividad: ¿cuál es su lugar preferido de barrio Amón? y ¿qué aspecto destacaría del barrio?, mediante un dibujo, elaborado sobre papel bond en un formato carta o tabloide y con técnica libre. 


\section{Percepción del paisaje: Redibujá Amón}

Esta actividad fue relacionada con el segundo objetivo de Dibujando Amón y profundiza en la valorización de los elementos del PUHBA. Se utilizaron siete fotografías del perfil urbano (con un largo de $1.10 \mathrm{~m}$ ) y diez perspectivas (11x17 pulgadas) de las calles de barrio Amón, las cuales fueron plastificadas y distribuidas a lo largo del vestíbulo del primer piso. Se les solicitó a los participantes que al escoger una o varias imágenes: marcaran, redibujaran, resaltaran o tacharan, aquellos elementos del PUHBA que les gusta (con marcador verde), que no les gusta (con marcador rojo), y que cambiarían (con marcador negro); ya sea que eso que quieran cambiar esté o no presente en la imagen seleccionada.

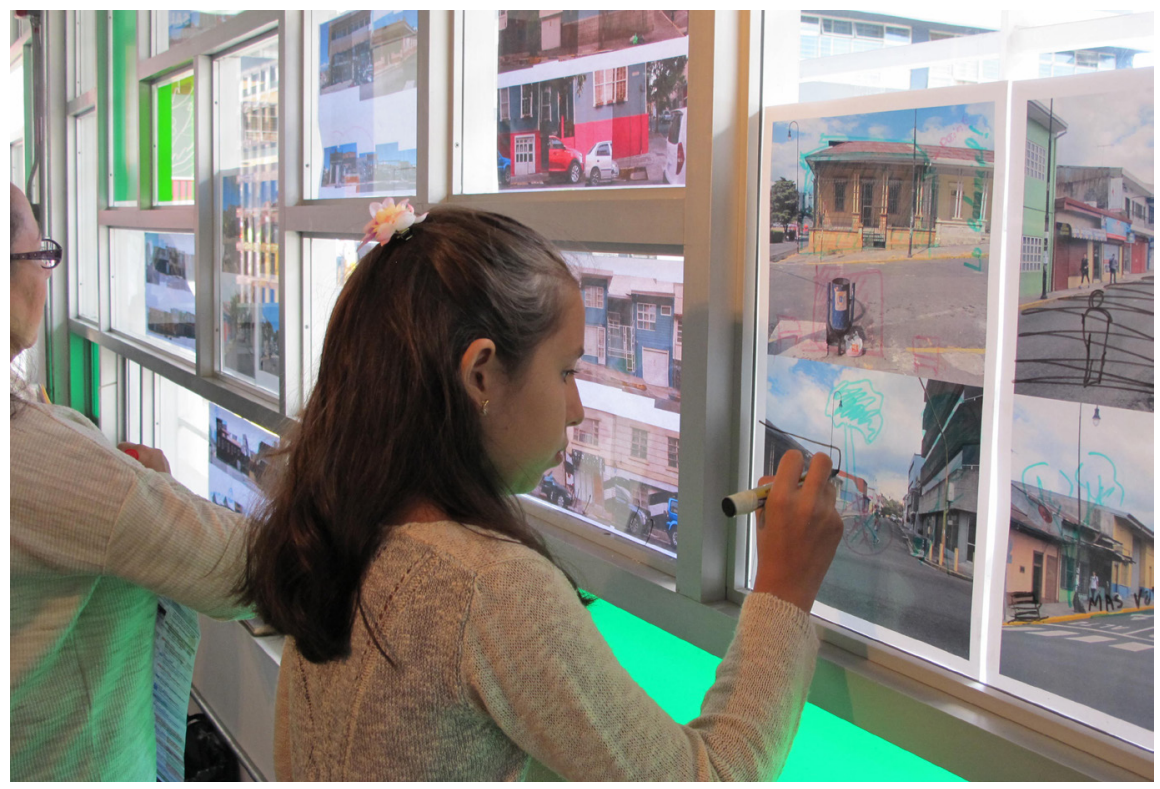

Imagen 04: niña participando de la actividad "Redibujá Amón". Para conocer la percepción del paisaje del barrio, se les invitó a los participantes a marcar, redibujar, resaltar o tachar en imágenes actuales del barrio, según un código de colores, aquellos elementos del paisaje urbano histórico que les gustaba o no, e inclusive podrían hacer una propuesta de lo que cambiarían.

Fuente: Proyecto de investigación Amón_RA. 
Imagen del barrio: Imagínate en Amón

"Imagen del barrio" se vinculó al tercer objetivo de Dibujando Amón, con el cual se pretendió identificar la morfología del barrio desde la perspectiva de quien lo habita y visita, a través de la elaboración de una cartografía social basada en los elementos de la imagen de la ciudad propuestos por Lynch. Mediante tres mapas plastificados de $1.10 \times 1.10$ metros, uno donde se combinó la imagen satelital y el levantamiento de calles, avenidas y cuadras del barrio con la ubicación de los nueve edificios patrimoniales de la zona en cuestión y colocado en un lugar visible por los visitantes a la actividad, sirviendo este como referencia y dos"pizarras mágicas" o mapas de contornos urbanos del barrio, ubicados en dos mesas, se le solicitó al visitante que identificara:

- Sendas: donde se debía marcar en el mapa, con marcador verde, los recorridos que sigue el observador (entiéndase el habitante, usuario o visitante del barrio) normal, ocasional o potencialmente dentro del barrio.

- Bordes: se solicitó dibujar en el mapa, con marcador rojo, aquellos elementos lineales que el observador no usa o no considera una senda, si no que impiden una transición en el espacio.

- Nodos: se pidió identificar, con marcador negro, aquellos puntos estratégicos del barrio a los que el observador puede ingresar y que constituyen los focos intensivos de los que parte o a los que se encamina.

- Hitos: se solicitó identificar, con marcador azul, los puntos de referencia que el observador reconoce, pero no entra en ellos, sino que le son exteriores. Esto implica una selección de un elemento entre una multitud de posibilidades.

Para la cada una de las anteriores actividades se fotografió los resultados, registrando si es habitante, usuario (trabaja o estudia en Amón) o visitante del barrio.

23. Pizarras mágicas: son mapas del barrio, los cuales están plastificados para que, con marcadores lavables, las personas dibujaran sobre estos y luego pudieran borrar la imagen. 


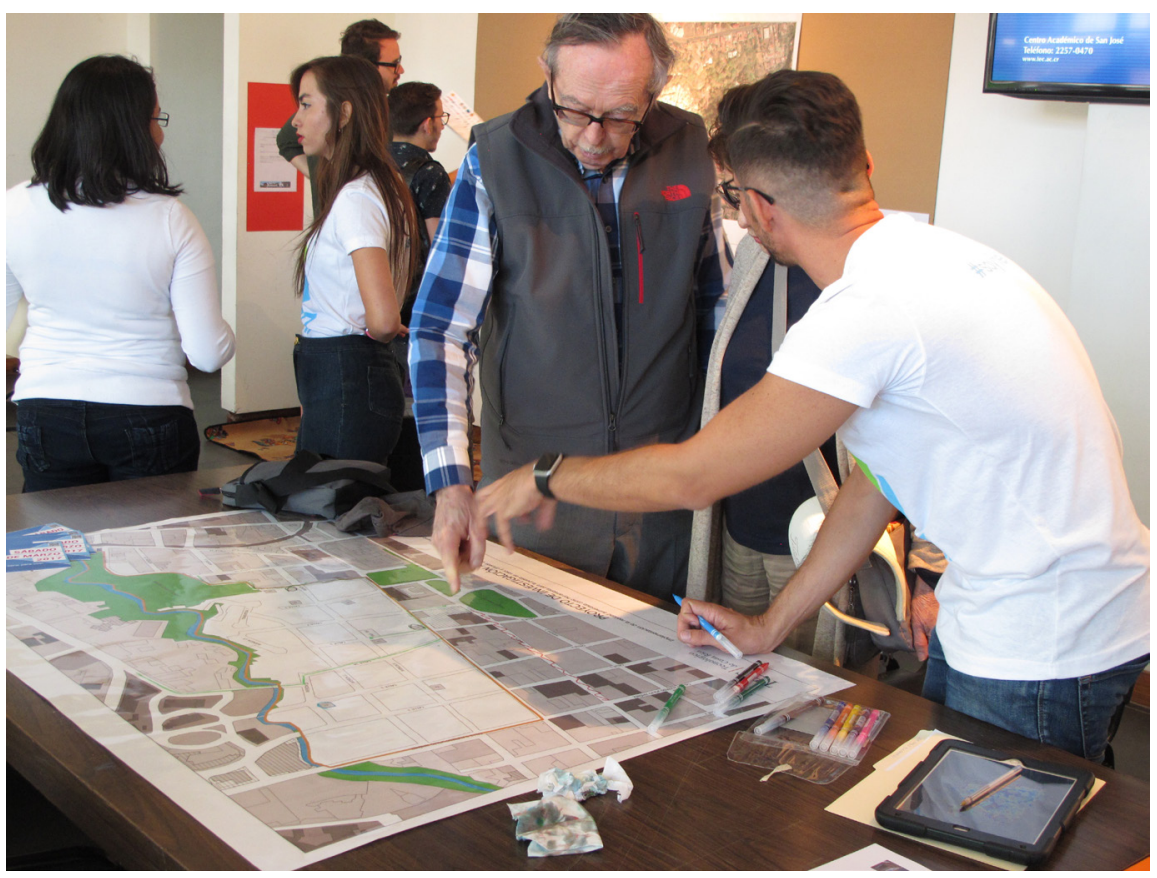

Imagen 05: antiguos vecinos del barrio que participaron de la actividad "Imagínate en Amón". En esta actividad los participantes marcaron en mapas del contorno urbano de la zona en estudio, mediante una codificación de colores, los bordes, sendas, hitos y nodos de Amón, con el fin de conocer la imagen de barrio.

Fuente: Proyecto de investigación Amón_RA. 


\section{TALLERES DEL SEGUNDO SEMESTRE 2017}

\section{Primer taller}

En el primer taller, realizado el 26 de octubre, se validó y corrigió información de la línea del tiempo elaborada por el equipo de investigación; además, se identificaron puntos importantes del barrio, ya sea porque ocurrieron acontecimientos históricos, o porque la comunidad les otorga un valor que los convierte en referentes urbanos. Por último, en este taller se realizó una comprobación de las posibles funcionalidades de la aplicación móvil.

\section{Actividad 1: "La pared del tiempo"}

Esta actividad fue diseñada y dirigida por el Dr. Arq. David Porras y el objetivo fue corroborar la veracidad de los hitos históricos del barrio identificados en la investigación previa, así como recopilar más información mediante el aporte de los participantes en el taller. El equipo de investigación elaboró una línea del tiempo con la información obtenida de fuentes primarias. Sin embargo, era importante que esta reconstrucción histórica fuese corroborada y robustecida por los vecinos y usuarios del barrio, ya que al ser esta línea del tiempo estructurada a partir de la información documental que logró identificarse, muchos elementos del contexto y de tipo vivencial pudieron haberse omitido y que pudieron ser recopiladas a través de las antropofuentes, lo cual se contempló como una oportunidad de enriquecer la experiencia de RA que ofrece la aplicación móvil.

Para esto se proyectó una línea del tiempo elaborada en el software Tiki-Toki ${ }^{24}$. Se les solicitó a los participantes tomar esto como referencia y se le repartieron papeles de colores para que describieron brevemente aquel evento que consideren relevante de incluir en la aplicación o corregir aquellos aspectos históricos que fuesen imprecisos. Además, se les pidió a las personas participantes, pegar el papel en una composición análoga de la línea del tiempo virtual, ubicada sobre una de las paredes del auditorio donde se realizó la actividad, es decir en la "Pared del tiempo". Ello permitió una interacción entre los participantes y un aporte del contenido contextual que no reflejaba la línea de tiempo propuesta por el equipo del proyecto.

24. Tiki-Toki es un servicio web que permite crear líneas de tiempo interactivas, añadiendo imágenes y videos. Esta plataforma tiene una versión libre de uso que permite crear una sola línea de tiempo y otra de pago que le permite crear más líneas de tiempo y hacer un trabajo colaborativo. 


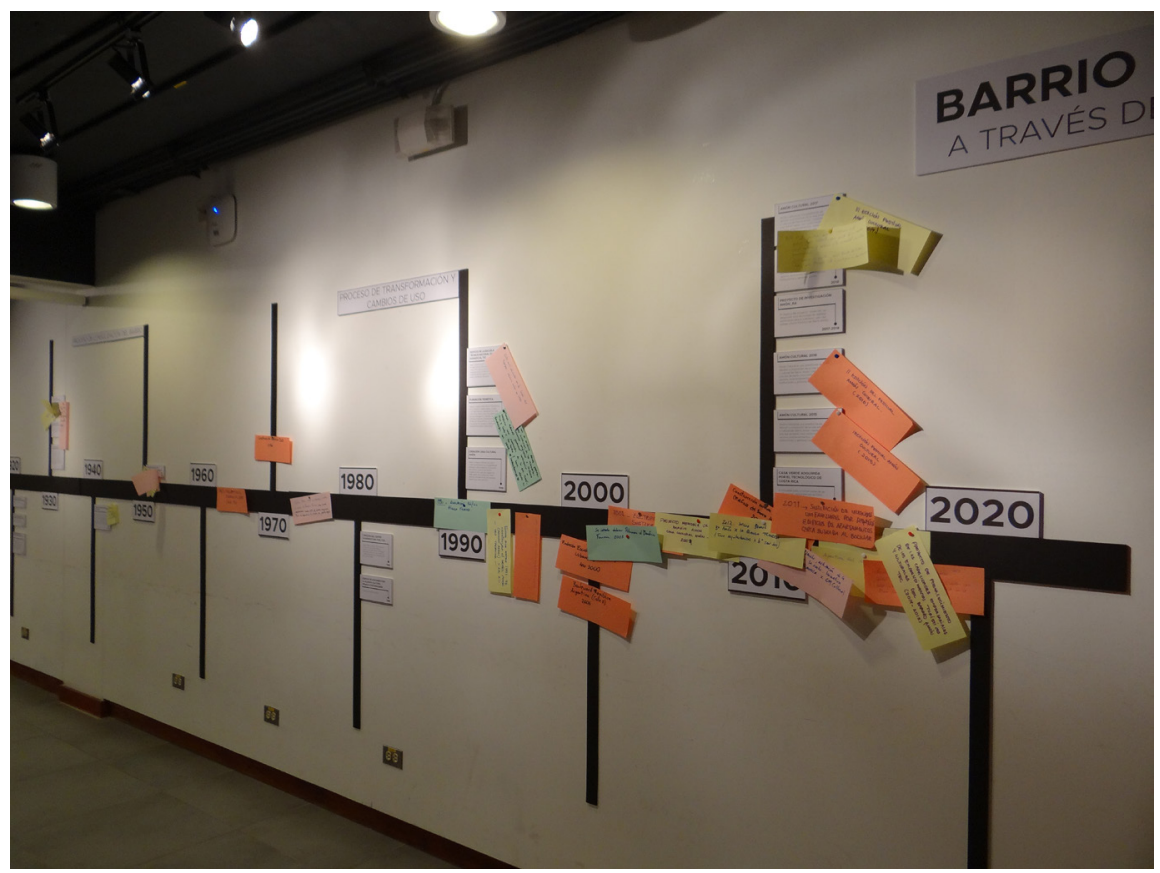

Imagen 06: resultados de la actividad "Pared del tiempo", los cuales corresponden a eventos que los participantes del taller consideraron importantes incorporar a la "Línea del tiempo" propuesta por el equipo investigador. Dichos resultados se incorporaron como contenido para la aplicación móvil.

Fuente: Proyecto de investigación Amón_RA.

\section{Actividad 2: "¿Cómo es nuestro barrio?"}

La Dra. Arq. Kenia García Baltodano fue quien planificó la segunda actividad, cuyo objetivo fue identificar puntos de referencia o de interés dentro de barrio Amón, a partir de la vivencia de los actores sociales. Utilizando los proyectores ubicados en el salón se presentó a los participantes los elementos que fueron identificados como referentes o puntos de interés en Barrio Amón, y que tomaron como fuente la información recolectada en el ejercicio participativo llevado a cabo en "Dibujando Amón". Posteriormente se les solicitó a los participantes 
que se distribuyeran en subgrupos de cuatro o cinco personas, con la intención de tener diversidad de los informantes. Cada grupo se ubicó en una estación de trabajo con un mapa del barrio impreso en papel, se empleó vinil adhesivo de colores para identificar los puntos de referencia, marcadores y hojas de papel donde escribieron el nombre de los elementos identificados.

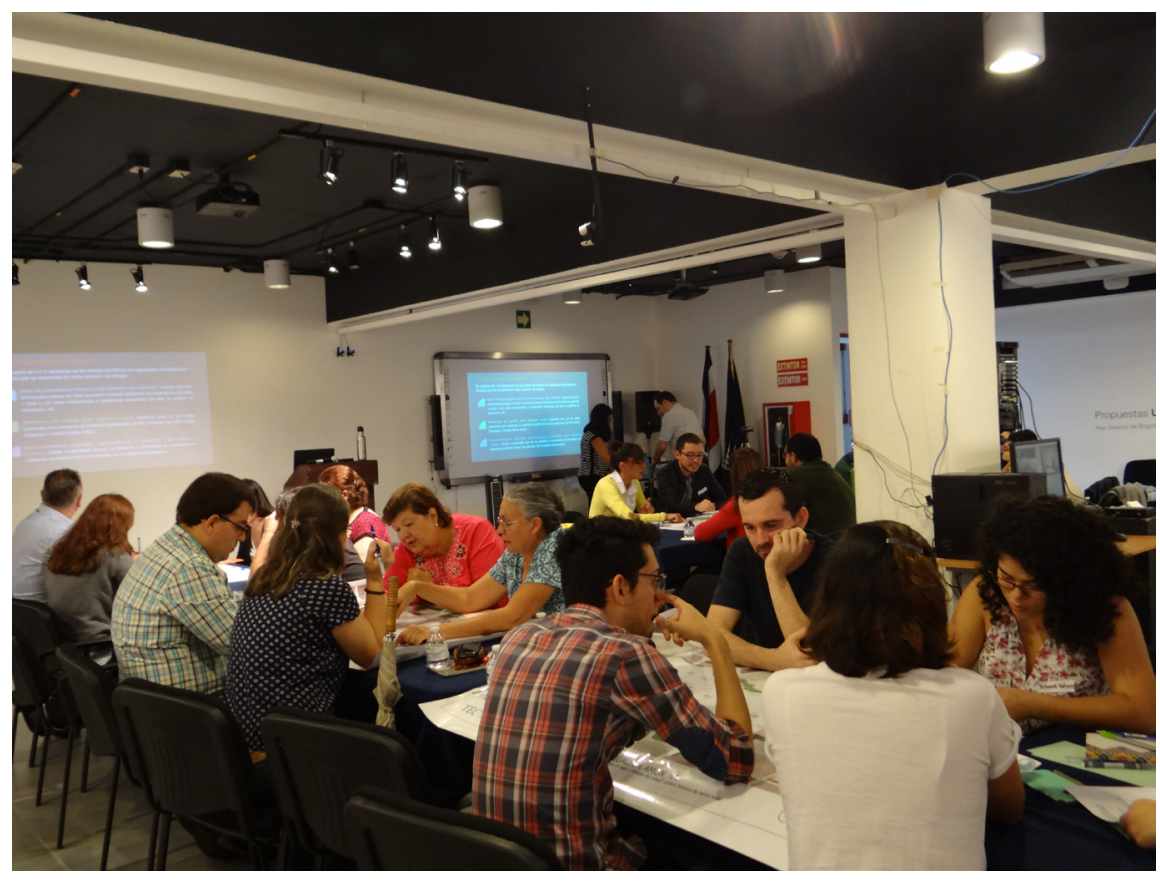

Imagen 07: participantes del taller 1 en la actividad ¿Cómo es nuestro barrio? En ella se identificaron puntos de referencia o de interés dentro del barrio, a partir de la vivencia de los actores sociales.

Fuente: Proyecto de investigación Amón_RA. 
Se les solicitó a las personas invitadas que identificaran los puntos de interés o referencia del barrio de la siguiente manera:

- Sitios de importancia histórica (vinil adhesivo gris azulado): lugares que son reconocidos porque en ellos ocurrieron eventos históricos de importancia nacional o local o por estar relacionados a personajes relevantes del arte, la política, la educación, etc.

- Referentes del pasado (vinil adhesivo verde): espacios que, ya no están presentes, pero marcaron un momento significativo de las personas que han vivido, trabajado o visitado barrio Amón.

- Emprendimientos culturales, gastronómicos y turísticos (vinil adhesivo rosado): locales comerciales que por su tradición o innovación se convierten en referentes de barrio y se vinculan con el objetivo del proyecto.

Actividad 3: ¿Cómo te imaginas Amón_RA? Taller de Comprobación de Funcionalidades

Esta actividad fue diseñada por la $\mathrm{Mstr}^{25}$. $\mathrm{Dl}^{26}$. María del Carmen Valverde. Su objetivo fue comprobar que los supuestos, requerimientos y funcionalidades identificadas por el equipo de investigación para la aplicación móvil, eran realmente lo que los potenciales usuarios visualizan para Amón_RA. Para esta actividad se utilizó la metodología de requerimientos y diseño de interfaces que utiliza el TEC Digital ${ }^{27}$,

\section{Mstr.: Máster}

\section{DI: Diseñadora Industrial}

27. EI TEC Digital es una plataforma tecnológica que posee el Tecnológico de Costa Rica, la cual brinda información para los estudiantes como, por ejemplo: malla curricular, horarios de clase, noticias, documentos compartidos, foros, entre otros. Para los profesores esta plataforma le sirve para comunicarse con los estudiantes, poner las clases a disposición de estos, así como llevar un control de las evaluaciones. Además, el TEC Digital, como departamento, da soporte de asistencia y capacitación, asesoramiento y generación de recursos educativos para el proceso de enseñanza - aprendizaje (Instituto Tecnológico de Costa Rica, 2019). El equipo técnico de este departamento está integrado por diversos profesionales, entre ellos Diseñadores Industriales que han aportado en la creación de metodologías de trabajo para el desarrollo de componentes de la plataforma. 
elaborada porla Ing. DI.Andrea Calvo-Elizondo (2017). Este planteamiento se basa en las metodologías de:

- Lean Startup Method (Método de inicio acortado), cuyo enfoque se basa en crear nuevos productos y entregarlos en las manos de los clientes más rápido.

- Minimum Viable Product (Mínimo Producto Viable), esta metodología evalúa el aporte de las funciones durante el proceso para generar la mayor cantidad de retorno en cuanto a una experiencia con el mínimo esfuerzo.

- User Experience (Experiencia de Usuario) que reduce los costos y el tiempo de desarrollo, incrementando la satisfacción del usuario y la facilidad de uso.

La filosofía se basa en poder involucrar a los usuarios de un sistema, desde los inicios de la definición de este a nivel de funcionalidades y contenidos. Lo anterior para captar las verdaderas necesidades de los usuarios y clasificarlas de modo que el equipo investigador pudiera determinar qué podría ofrecer la aplicación móvil. 


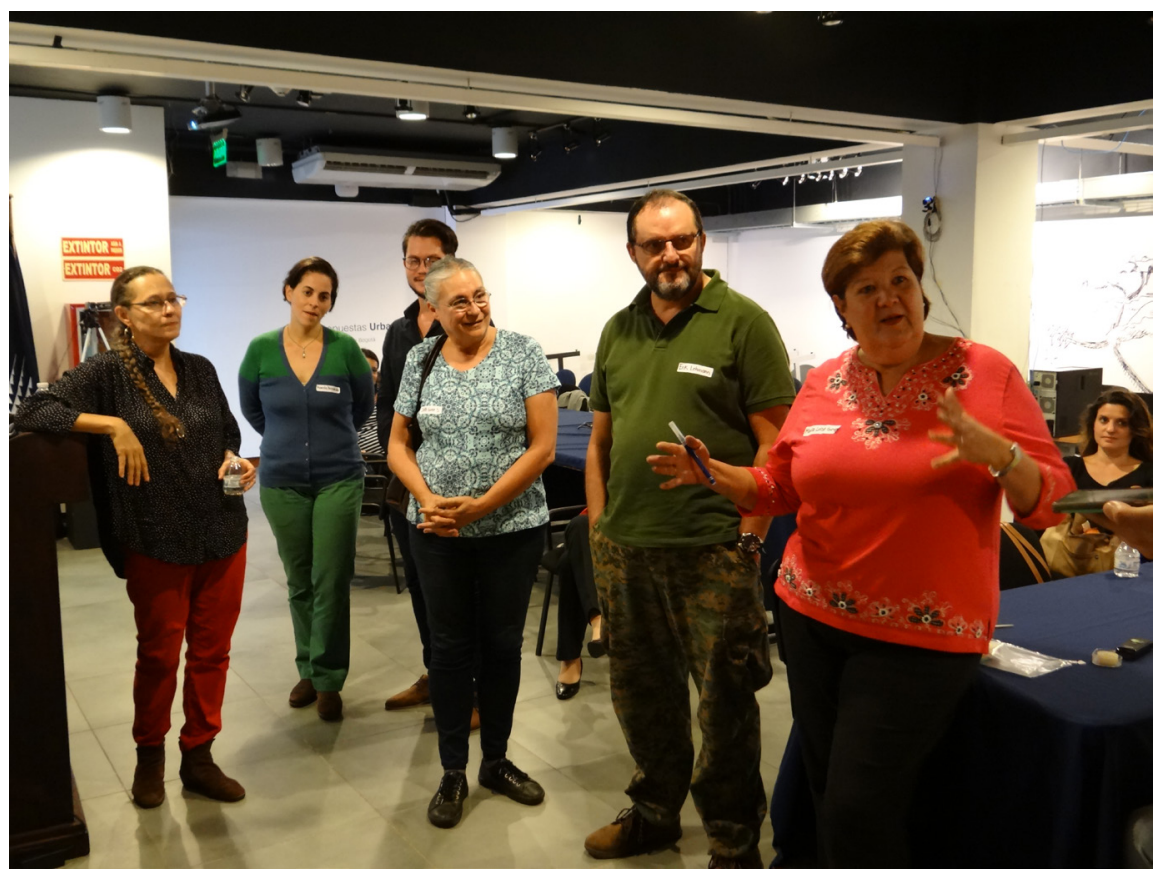

Imagen 08: participantes del taller 1 en la actividad ¿Cómo te imaginás Amón_RA? En esta imagen los participantes revisan los resultados de la validación de los supuestos, requerimientos y funcionalidades identificadas por el equipo de investigación para la aplicación móvil.

Fuente: Proyecto de investigación Amón_RA.

Previo a la realización del taller se realizó una actividad con miembros del equipo investigador donde se buscó identificar cuál era la percepción sobre aspectos como, por ejemplo: cuál es el objetivo de la aplicación móvil, quiénes son los usuarios, qué debe de contener, qué es lo indispensable. Con base en estas dos últimas preguntas y en un cuadro de mínimos comunes ${ }^{28}$ se procedió a identificar cada funcionalidad y escribirla en un post it (notas adhesivas), de modo que se reflejarán todos los aportes brindados por el equipo. Clasificando posteriormente cada funcionalidad en tres categorías o láminas, a saber:

28. Resumen que consolida toda la información que se ha recopilado en un análisis de referencia enlistando las necesidades que son comunes a la mayoría de las aplicaciones analizadas (Hernández-Castro, 2016). 
- Must have: indispensables, en cualquier versión de la aplicación móvil.

- Want to have: elementos que aportan valor, pero no son indispensables para la aplicación móvil.

- Nice to have: no aportan gran valor para el usuario en las circunstancias actuales.

A los asistentes al taller se les explicó qué es una funcionalidad (contenido o función que puede tener la aplicación móvil). Y se les indicó que se iba a leer cada una las funcionalidades identificadas y que podían cambiar de clasificación de la funcionalidad, eliminar o agregar nuevas funcionalidades.

\section{Segundo taller}

El 9 de noviembre se realizó el segundo taller donde se ejecutaron tres actividades: en la primera se recolectó información anecdótica vinculada a los nueve inmuebles con declaratoria de patrimonio histórico arquitectónico presentes en barrio Amón. Posteriormente, se desarrolló una actividad donde se pudo relacionar una serie de fotografías antiguas con el contexto físico, histórico y anecdótico. En la tercera parte del taller se validó los términos o nomenclatura que los potenciales usuarios de la aplicación usarían para nombrar secciones o contenidos, así como validar la posible estructura u organización de estos en la aplicación móvil.

\section{Actividad 1: "Afiche anecdótico"}

Esta primera actividad fue coordinada por el Mstr. Arq. Tomás Martínez Baldares. Su objetivo fue complementar la información técnica y documental de cada uno de los afiches correspondientes a las edificaciones patrimoniales, del barrio, con información anecdótica, desconocida o con aquellos sucesos no registrados. Se inició el taller organizando grupos de trabajo conformados por cuatro o cinco personas. El medio utilizado fue el programa Padlet ${ }^{29}$, herramienta idónea para

29. Padlet es una plataforma digital que permite crear murales colaborativos, ofreciendo la posibilidad de construir espacios donde se pueden presentar recursos multimedia, ya sea videos, audio, fotos o documentos. Estos recursos se agregan como notas adhesivas, como si fuesen "post-its". Este software es de uso libre. 
procesos en los que se utiliza información surgida en dinámicas de taller y de un trabajo colaborativo por los participantes. A partir de la referencia de afiches elaborados para las edificaciones con declaratoria de patrimonio histórico - arquitectónico de la exposición “Descubriendo Amón" ${ }^{30}$, cada grupo de trabajo seleccionó entre dos y tres afiches; la actividad consistió en aportar a dicha información, material anecdótico a cada afiche, mediante la respuesta a las preguntas generadoras expuestas en la Tabla 1.

Tabla 1. Aspectos a considerar en el afiche anecdótico.

\begin{tabular}{l|l}
\hline Aspecto & Pregunta generadora \\
\hline Anécdotas (Familiar - Interno) & $\begin{array}{l}\text { ¿Conoce alguna anécdota o evento } \\
\text { asociado/a a la casa? }\end{array}$ \\
\hline Personajes & $\begin{array}{l}\text { ¿Quiénes habitaban la casa? } \\
\text { ¿Quiénes la visitaban? }\end{array}$ \\
\hline Sucesos (Barrial - Entorno) & $\begin{array}{l}\text { ¿Qcurrió algo relevante en la casa o } \\
\text { fuera de ella? }\end{array}$ \\
\hline Percepción & $\begin{array}{l}\text { ¿Qué pensaban los vecinos de esta } \\
\text { casa? }\end{array}$ \\
\hline Recomendación & $\begin{array}{l}\text { ¿Qué agregaría o modificaría al } \\
\text { poster? }\end{array}$ \\
\hline $\begin{array}{l}\text { Sugerencias de modificación o } \\
\text { información por complementar }\end{array}$ & ¿Detecta algún detalle erróneo en la \\
\end{tabular}

Fuente: Proyecto de investigación Amón_RA. 


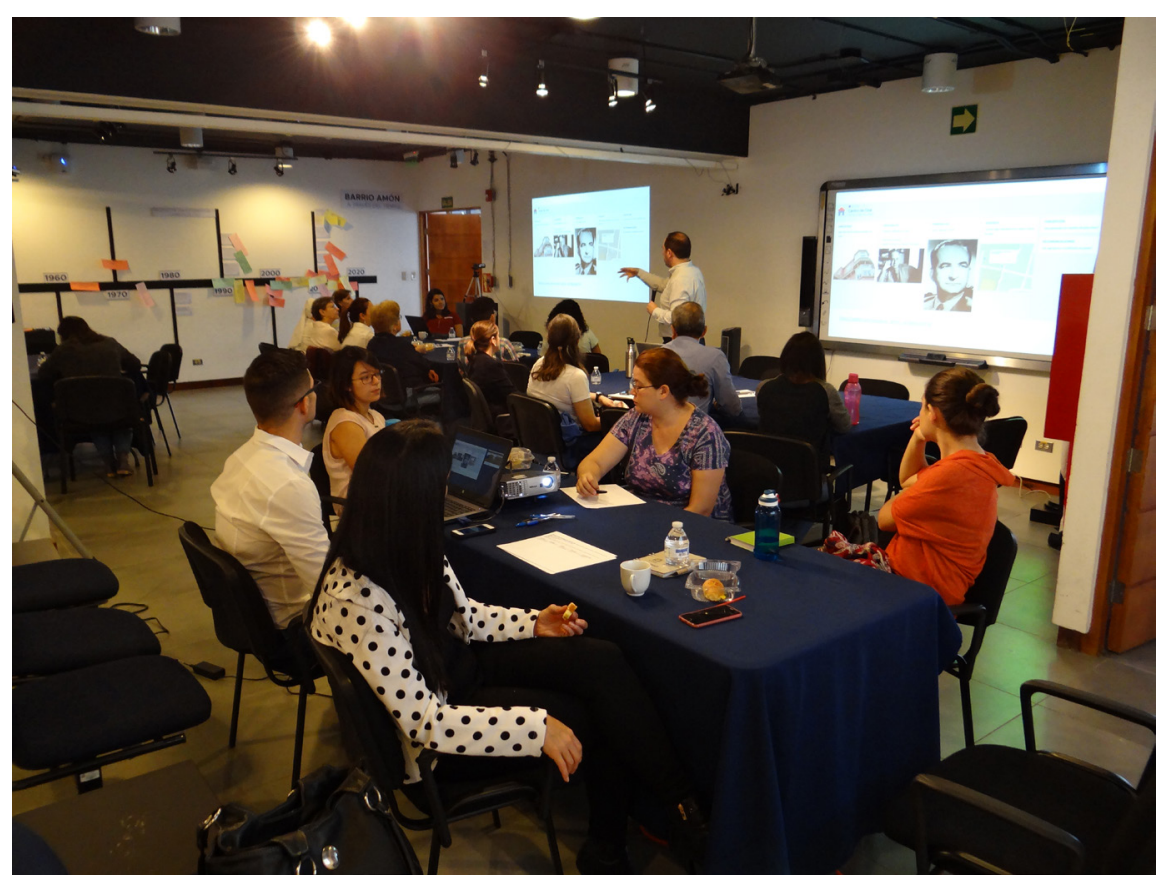

Imagen 09: participantes del taller escuchando la explicación de la actividad "Afiche anecdótico", en la cual, mediante el programa Padlet se registraron anécdotas ligadas a diferentes viviendas y personajes de barrio Amón.

Fuente: Proyecto de investigación Amón_RA.

\section{Actividad 2: "Fotos e identidad"}

La segunda actividad fue diseñada y dirigida por el Mstr. Arq. Jose Pablo Bulgarelli Bolaños. El objetivo fue recopilar información asociada a las vivencias de quienes habitan o habitaron barrio Amón a partir de fotos antiguas. Parte importante del Paisaje Urbano Histórico son todas aquellas capas de información que se van formando a lo largo del tiempo en todos los contextos de investigación: el natural, el urbano, el social, el económico, el legal, el cultural y el perceptual. La fotografía, ligada a un contexto, es un recurso que permite identificar varios elementos del PUHBA en un momento específico de la historia, de ahí la importancia de 
compilar no solo las fotografías, si no también contextualizar el momento en que fueron tomadas, localizar cada punto desde donde fueron realizadas y dotar de más material que podría ser utilizado en la aplicación.

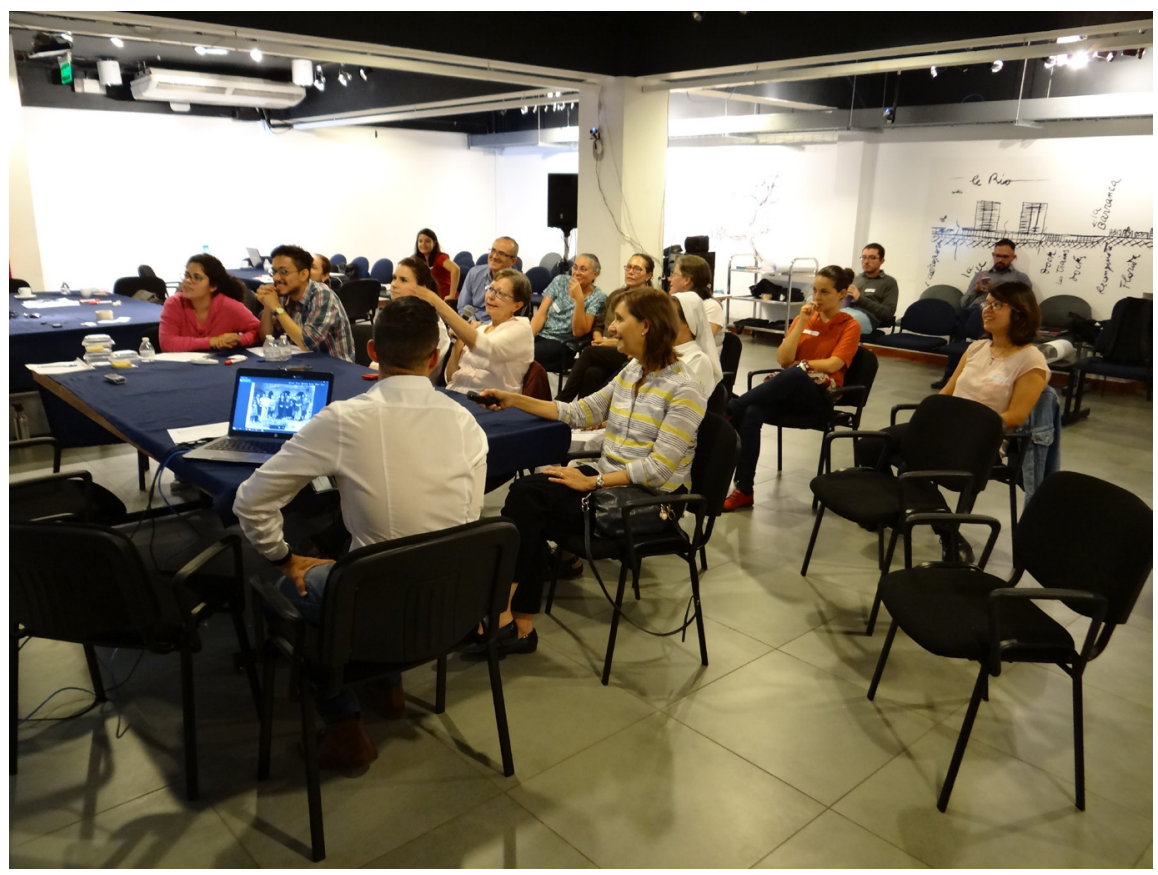

Imagen 10: participantes del taller escuchando a doña Carmen Odio González (mujer con la mano levantada) contando una anécdota ligada a la imagen proyectada, parte de la actividad "Fotos e identidad".

Fuente: Proyecto de investigación Amón_RA.

\section{Actividad 3: Card Sorting}

Los términos y estructura propuesta en la arquitectura alpha ${ }^{31}$ de una aplicación móvil deben de ser validados por los potenciales usuarios, de manera que se compruebe si los términos utilizados son comprendidos por estos, así conocer cómo ordenan los términos y qué nombre le asocia a cada agrupamiento de contenidos. La técnica

31. Es el orden que se da a los contenidos de una aplicación, generalmente se representa como una gráfica donde se muestran las secciones y sus correspondientes contenidos. 
empleada para la validación fue el Card Sorting (clasificación de tarjetas). Esta técnica consiste en que los testers (potenciales usuarios de la aplicación móvil, quienes participan en la prueba) agrupen tarjetas que tienen contenidos de la arquitectura alpha. Previo a realizar la prueba se requiere definir los contenidos de la aplicación y se omite poner términos como cancelar, aceptar; ya que estas son acciones muy comunes para el contenido de una aplicación móvil. El objetivo de esta prueba es validar la nomenclatura y la estructura de los contenidos de la aplicación según Hernández-Castro (2016).

La actividad la coordinó la Mstr. DI. María del Carmen Valverde, quien les explicó a los participantes qué es un Card Sorting y su función. Para realizar la prueba de Card Sorting se formaron seis grupos de trabajo con los asistentes al taller, a cada uno de los grupos se le brindó una lámina de papel periódico, un juego de tarjetas con los términos de contenidos de la arquitectura alpha, un juego de tarjetas en blanco, tres hojas tamaño carta, un marcador y cinta adhesiva. Se les indicó a los participantes que separaran el juego de tarjetas y decidieran cómo deberían de agruparse, tomando en cuenta que estas tarjetas son los contenidos que tendría la aplicación. El tipo de Card Sorting utilizado para la actividad fue del tipo: abierto; es decir, que los participantes podían quitar o agregar más términos de los que se les brindó. Para esto se les dio tarjetas en blanco, de modo que pudieran anotar el nuevo término. En caso de eliminar términos, se les solicitó a los participantes que en las hojas tamaño carta pegaran los términos que dejaron por fuera y brindaran una breve justificación del por qué. Así como en el caso de agregar términos justificar el por qué. 


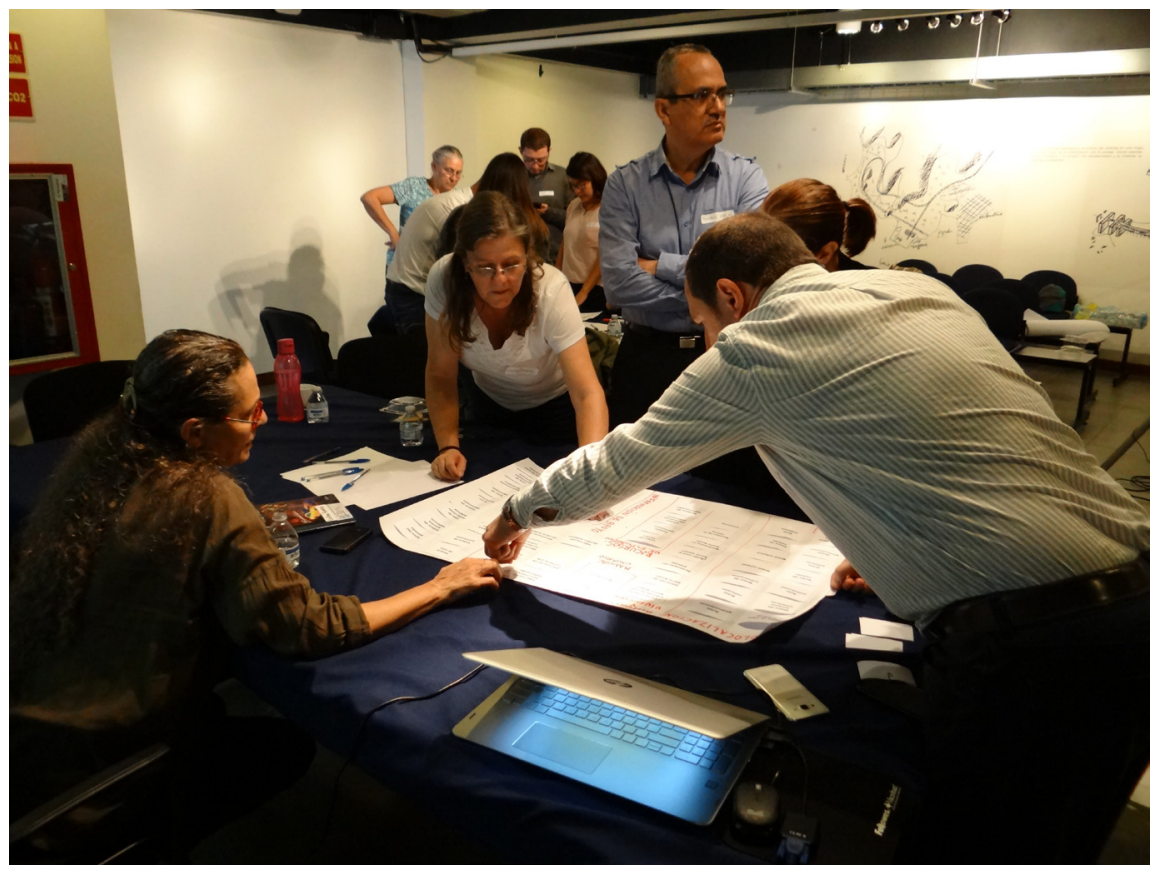

Imagen 11: participantes del taller en la actividad "Card sorting". Esta técnica consistió en que los participantes agruparan las tarjetas que tienen contenidos de la arquitectura alpha y así validar la nomenclatura y la estructura de los contenidos de la aplicación.

Fuente: Proyecto de investigación Amón_RA.

\section{Tercer taller:}

El último taller, ejecutado el 7 de diciembre del 2017, consistió en validar tanto la arquitectura de la información alpha y la nomenclatura de la aplicación móvil, así como el reconocimiento de patrones de diseño ${ }^{32}$, jerarquía y secuencia de lectura. A continuación, se profundiza sobre las metodologías abordadas en el taller participativo.

32. Patrón de diseño es un elemento estándar de interacción, que el usuario reconoce para interactuar con el sistema. Por ejemplo, la flecha para regresar tiene un forma y posición predeterminada, lo que hace que el usuario sepa casi que por experiencias previas para qué sirve el símbolo y qué acción va a realizar el sistema. 


\section{Actividad 1: Digital Prototyping}

Para este ejercicio se generó una maqueta a escala de grises y se utilizó el software Invision ${ }^{33}$ para contar con una propuesta digital que les permitiera a los potenciales usuarios la interacción con el prototipo de la aplicación móvil. Se hizo uso de grises con el propósito que los potenciales usuarios se concentraran en aspectos de jerarquía y secuencia de lectura de los patrones de diseño. Es decir, se evitó el uso del color para que no fuese un aspecto distractor. La actividad fue diseñada y coordinada por la Mstr. DI. María del Carmen Valverde. Para realizar la prueba se definieron algunos escenarios de uso, que los potenciales usuarios accedieron por medio de la maqueta. Algunas de las tareas planteadas para los usuarios fueron:

1. Usted se encuentra en barrio Amón, tiene la App Amón_RA y desea acceder a la RA. ¿Dónde y cómo encontraría la RA de la App? Objetivo de la tarea: Acceder la RA de la aplicación.

2. Usted desea conocer la evolución de barrio Amón a través del tiempo. ¿Dónde encontraría la información? Objetivo de la tarea: Acceder a la línea de tiempo.

3. Usted desea conocer ¿Qué edificios en barrio Amón poseen declaratoria patrimonial? ¿Dónde y cómo llegaría al dato? Objetivo de la tarea: Conocer los edificios con declaratoria patrimonial.

Como disposiciones generales, las pruebas se podían realizar individuales o en parejas. A los primeros grupos de prueba se les brindó la opción de explorar la aplicación móvil y luego se le realizaron las pruebas. A los segundos grupos se les solicitó que contestaran de forma directa las tareas; es decir, sin darle un tiempo de conocimiento de la aplicación.

33. La operación básica del programa es que el usuario interactúe con pantallas digitales de la futura aplicación, las cuales deben ser previamente diseñadas con otro programa para hacer prototipos. De esta manera se pueden hacer modificaciones en funcionalidad de la aplicación en desarrollo. 


\title{
V. RESULTADOS
}

\author{
Dibujando Amón
}

Con respecto a la identificación de aquellos elementos del PUHBA más presentes en la conciencia de las personas que participaron en la actividad se rescata el reconocimiento de las obras arquitectónicas excepcionales del barrio, como el Castillo del Moro ${ }^{34}$, así como de otros inmuebles que por su estado de conservación o por el uso del edificio están posicionados en el imaginario, tales como la Alianza Cultural Franco Costarricense o Alianza Francesa ${ }^{35}$ y la Casa Saborío González, conocida como Casa Verde ${ }^{36}$. En la Imagen 12 se muestra tanto la ubicación de estas edificaciones, como los modelos tridimensionales de los edificios mencionados anteriormente, los cuales forman parte de los contenidos de la aplicación móvil.

34. Por medio de la declaratoria del 8 el noviembre del 2000 el Castillo del Moro, este inmueble se incorpora a la lista de inmuebles patrimonio histórico arquitectónico de Costa Rica. Se le considera a este inmueble como el ejemplo más representativo, en el país, de la arquitectura del estilo neomudéjar, caracterizado por la profusión de arcos en forma de herradura, una cúpula de bronce, ménsulas y mosaicos españoles; reproduciendo una pequeña fortaleza mudéjar (Presidencia de la República de Costa Rica \& Ministerio de Cultura y Juventud, 2000).

35. El edificio que ahora alberga la Alianza Cultural Franco Costarricense fue declarado patrimonio histórico arquitectónico el 28 de noviembre de 1997, ya que, además de ser un hito urbano, cultural y social debido a su labor de prospección cultural, el inmueble es un ejemplo de la arquitectura residencial de la ciudad de San José de finales del siglo XIX y principios del XX. Se considera que este inmueble puso de manifiesto la introducción de nuevos materiales y técnicas constructivas como el uso de hierro importado y la ventanería con vidrio (Presidencia de la República de Costa Rica \& Ministerio de Cultura y Juventud, 1997).

36. Este inmueble fue declarado patrimonio histórico arquitectónico el 14 de diciembre del 2017, debido a que presenta importantes valores históricos, culturas y contextual ya que fue construido durante la época del auge de la exportación cafetalera de Costa Rica. Según la declaratoria patrimonial, el estilo victoria presente en la obra representa los valores sociales e ideológicos de la élite social y económica costarricense de la época, lo cual se ve reflejado en sus elementos formales, estructurales y funcionales (Presidencia de la República de Costa Rica \& Ministerio de Cultura y Juventud, 2017). 


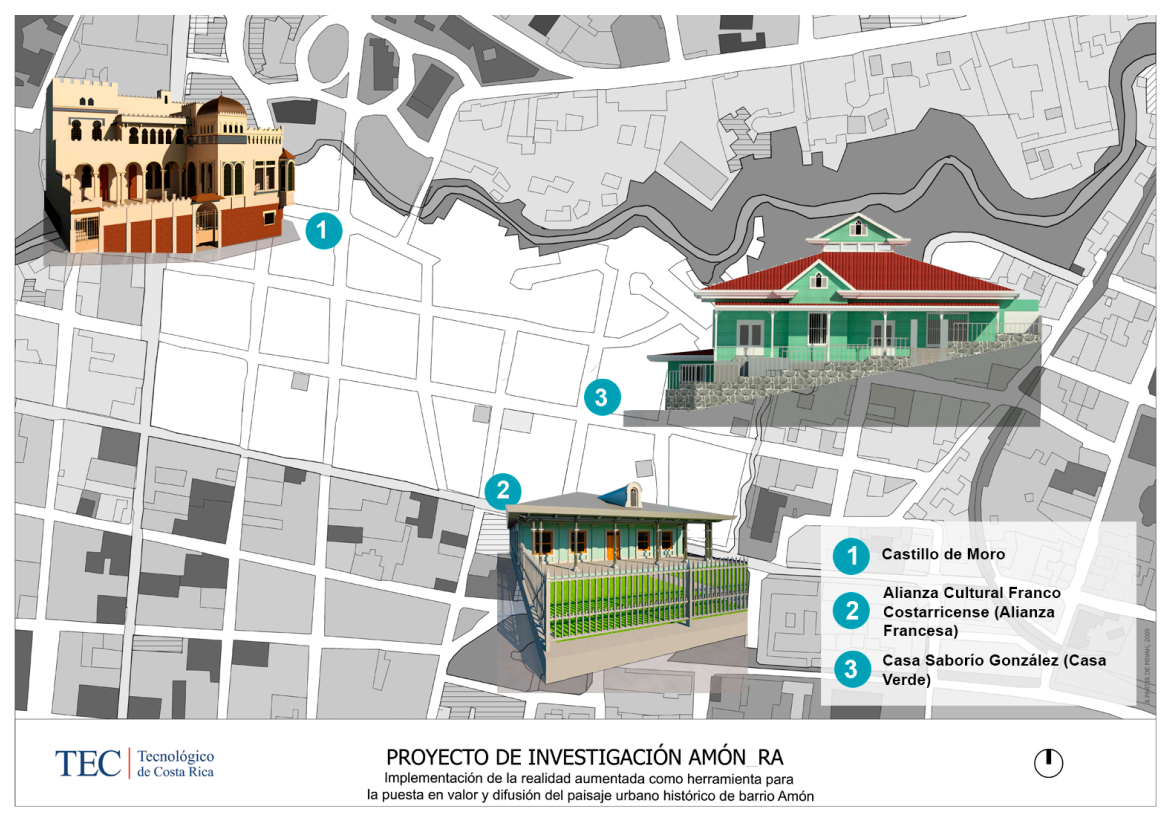

Imagen 12: plano con la ubicación de modelos tridimensionales de los objetos arquitectónicos reconocidos en barrio Amón por los asistentes a Dibujando Amón, 1: Castillo del Moro, 2: Alianza Cultural Franco Costarricense y 3: Casa Saborío González. Estos modelos son parte del contenido de la aplicación móvil.

Fuente: Proyecto de investigación Amón_RA.

Otras imágenes comunes fueron aquellas con elementos arquitectónicos influenciados por el estilo victoriano ${ }^{37}$, o que presentan alguna particularidad del barrio; así como también, escenas ambientadas en aquellos espacios urbanos como cafeterías y restaurantes. Los elementos naturales dentro del contexto urbano, es decir árboles en aceras y pequeños jardines al frente de algunas viviendas del barrio, así como los inmuebles en buen estado de conservación, fueron los más señalados como los componentes a conservar en las fotografías de perfil urbano y en las perspectivas de barrio Amón. Por otro lado, los participantes señalaron como elementos que no les parecen atractivos del barrio, a los automóviles y aquellos lugares cuya actividad comercial no se acopla a la dinámica barrial. Los componentes que se modificaron en las fotografías fueron principalmente las aceras, las cuales ampliaron y ambientaron con más vegetación.

37. Se entiende al estilo victoriano como aquel estilo predominante en la arquitectura anglosajona, así como en expresiones artísticas, durante el reinado de la reina Victoria de Gran Bretaña desde mediados del siglo XIX hasta principios del XX. Algunas características de este estilo son las pendientes altas en las cubiertas, las puertas de doble hoja y las ventanas de guillotina. 


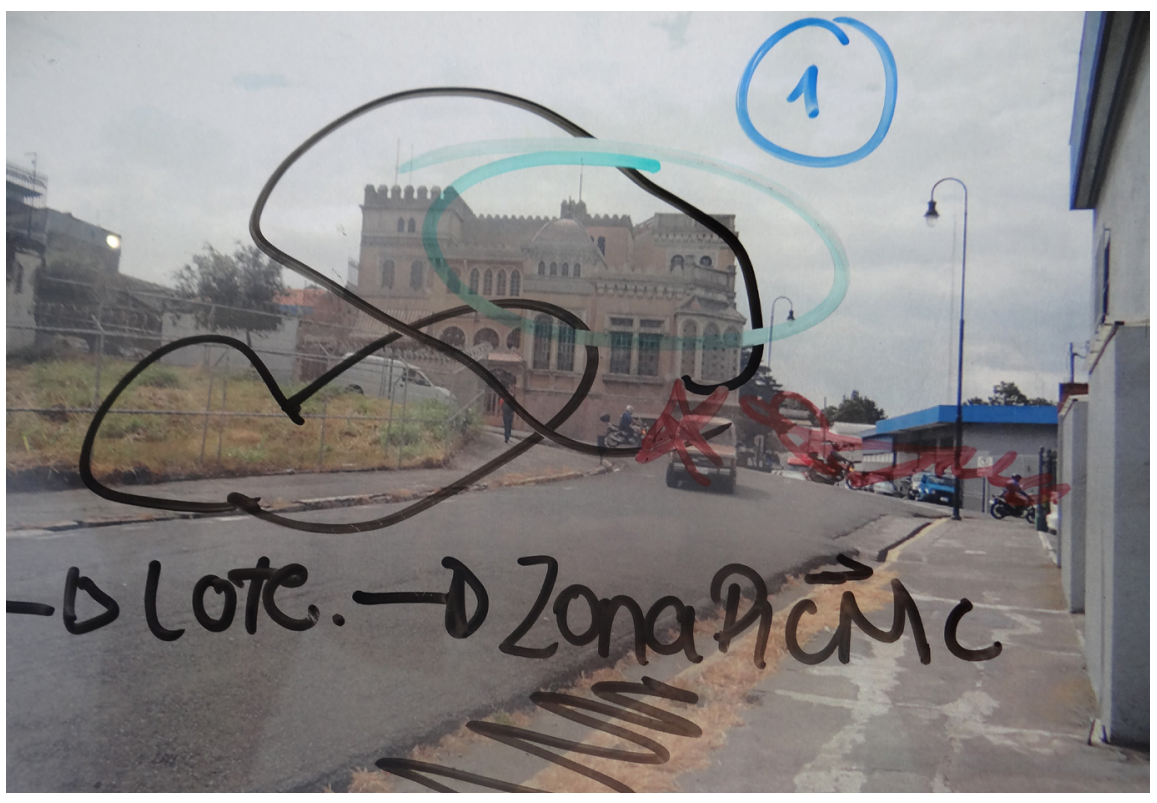

Imagen 13: resultado de la actividad "Redibujá Amón", en la cual la participante señaló como elemento importante el Castillo del Moro (encerrado en un círculo verde) y propuso cambios en el contexto urbano.

Fuente: Proyecto de investigación Amón_RA.

En la Imagen 13 se muestra uno de los resultados de "Redibujá Amón", donde el participante encierra en un circulo verde al Castillo del Moro indicando que es un elemento que considera importante y dibuja con marcador negro qué le gustaría que existiera en el contexto inmediato. Esto resulta interesante debido a que, como se presentará más adelante en este artículo, a pesar del reconocimiento de este elemento como valioso en el paisaje urbano, no se considera como un hito, e incluso se encuentra fuera de los límites perceptuales del barrio.

Se reconoce que los límites perceptivos de barrio Amón son muy distintos a los límites históricos y administrativos de este sector de la ciudad. Lo anterior debido al desconocimiento expresado por los participantes sobre los linderos municipales y al reconocimiento de otros lugares como bordes del barrio. Con el fin de contextualizar este trabajo, 
los límites administrativos se pueden apreciar en la Imagen 14, estos son: al Norte el río Torres, al Sur la avenida 7, al Oeste calle 0 y al Este la calle 11 ; sin embargo, históricamente el límite este fue calle 9.

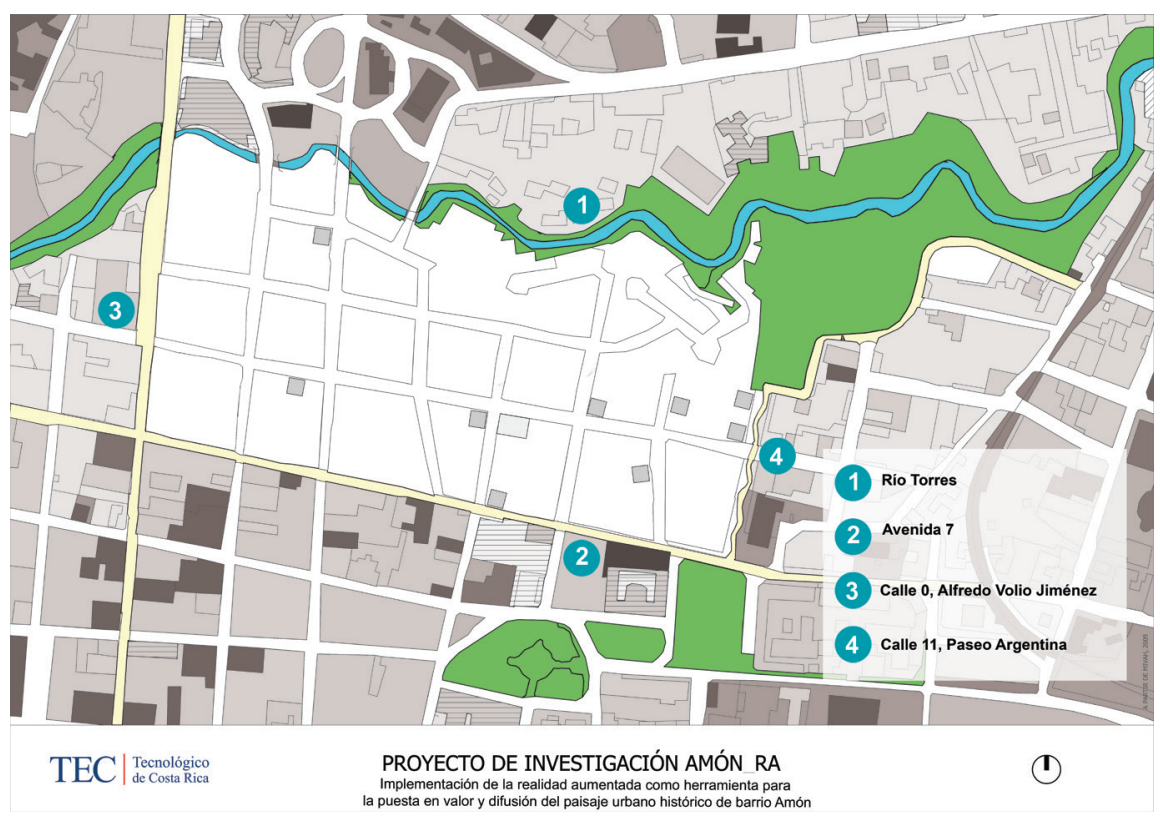

Imagen 14: plano de límites administrativos de barrio Amón.

Fuente: Proyecto de investigación Amón_RA.

La configuración perceptual de barrio Amón es muy distinta a la limitación administrativa, lo cual se puede observar en la Imagen 15. A partir de la constante identificación de las sendas, bordes, hitos y nodos por parte de los participantes en la actividad "Imagínate en Amón", donde se trabajó una cartografía social, es que el equipo de investigación determinó estos límites perceptuales. Los espacios públicos urbanos ubicados al Sur del distrito del Carmen, es decir el parque Morazán y parque España, como preámbulo urbano de barrio Amón, se consideran como parte del límite perceptual Sur, a pesar de que el primero se encuentra entre avenida 3 y 5 y el segundo entre avenida 5 y 7; configurando una limitación particular del barrio. 


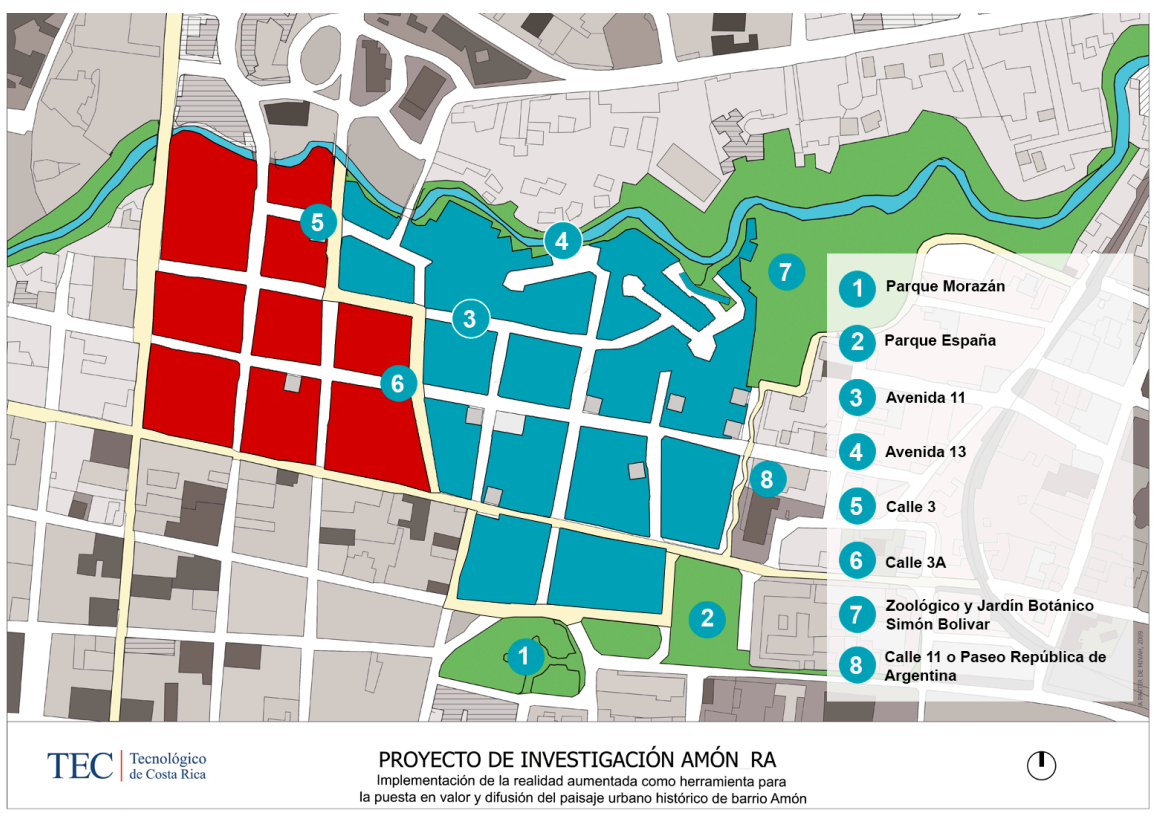

Imagen 15: plano de configuración perceptual de barrio Amón, cuyos límites son distintos a los formales. Para los participantes de "Dibujando Amón", ciertas zonas del barrio no le son significativas como, por ejemplo, la zona al este de la calle $3^{a}$; mientras que elementos urbanos fuera de los límites administrativos sí son incluidos, como el conjunto urbano de los parques Morazán, Jardín de Paz y España.

Fuente: Proyecto de investigación Amón_RA.

El límite perceptual Norte es difuso, ya que administrativamente el río Torres es lo que separa a barrio Amón del resto de la ciudad. Este elemento natural no es mencionado por ninguno de los participantes, lo que se considera por el equipo de investigación como una muestra de la tendencia de las ciudades del Valle Central de Costa Rica, a negar físicamente los cuerpos de agua ${ }^{38}$, y su relación con la percepción de los límites del Barrio Amón con el resto de la ciudad. En su lugar, los participantes, señalaron como bordes difusos la avenida 11 y 13. Inclusive muchos de estos desconocían la existencia de la avenida 13. Se identificaron como bordes al Oeste las calles 3 y $3 \mathrm{~A}$, debido a la percepción de inseguridad de los transeúntes en esa zona. La inseguridad de ese

38. Este fenómeno de negar los cuerpos de agua en las ciudades del Gran Área Metropolitana de Costa Rica es un tema que puede derivar en una investigación y responder a preguntas como: ¿podría existir alguna relación entre esos cuerpos de agua, con condiciones ambientales y la percepción de los límites de un barrio? Si existiera alguna relación ¿cuál sería el desafío de las entidades competentes en el diseño urbano? 
sector podría asociarse a que es poco habitada por personas y por la gran cantidad de tránsito vehicular, específicamente en calles 0,1 y 3.

Al Este se logra identificar como límites perceptuales el conjunto que se forma en el sector norte, desde el Zoológico y Jardín Botánico Simón Bolívar, al que no se considera como parte del barrio; en el este, la Calle 11 o paseo República Argentina, la cual posee una configuración ondulante, hasta el parque España al sur. Se identificaron como sendas de norte a sur las calles 3 y 5, así como las calles 9 y 11, mientras que de este a oeste prevalecieron las avenidas 7 y 9 como sendas claras de barrio Amón.

Con respecto a la identificación de los hitos del barrio, es importante recordar que se les solicitó a los participantes señalar los puntos de referencia que reconoce de barrio Amón, pero que no entran en ellos, sino que les son exteriores; lo cual implicó una selección de un elemento entre una multitud de posibilidades y con los cuales lograron no solo indicar que estos objetos pertenecen territorialmente al barrio, si no que con ellos logran generar una identidad y una ubicación del barrio dentro de la ciudad. Los hitos que se aprecian en la Imagen 16 fueron aquellos elementos mencionados durante la actividad "Imagínate en Amón" que se consideraron como parte de ese paisaje urbano histórico.

Los primeros tres elementos más mencionados fueron el edificio del Instituto Nacional de Seguros (INS), el del Instituto Nacional de Vivienda (INVU) y el TEC haciendo referencia al Campus Tecnológico Local San José. Estos tres edificios son los que poseen mayor altura y área ocupada dentro de los límites administrativos del barrio, lo que los vuelven un referente en la cotidianidad del barrio. Además, estos edificios son instituciones públicas posicionadas en el imaginario colectivo nacional, lo que facilita su identificación dentro del territorio. 


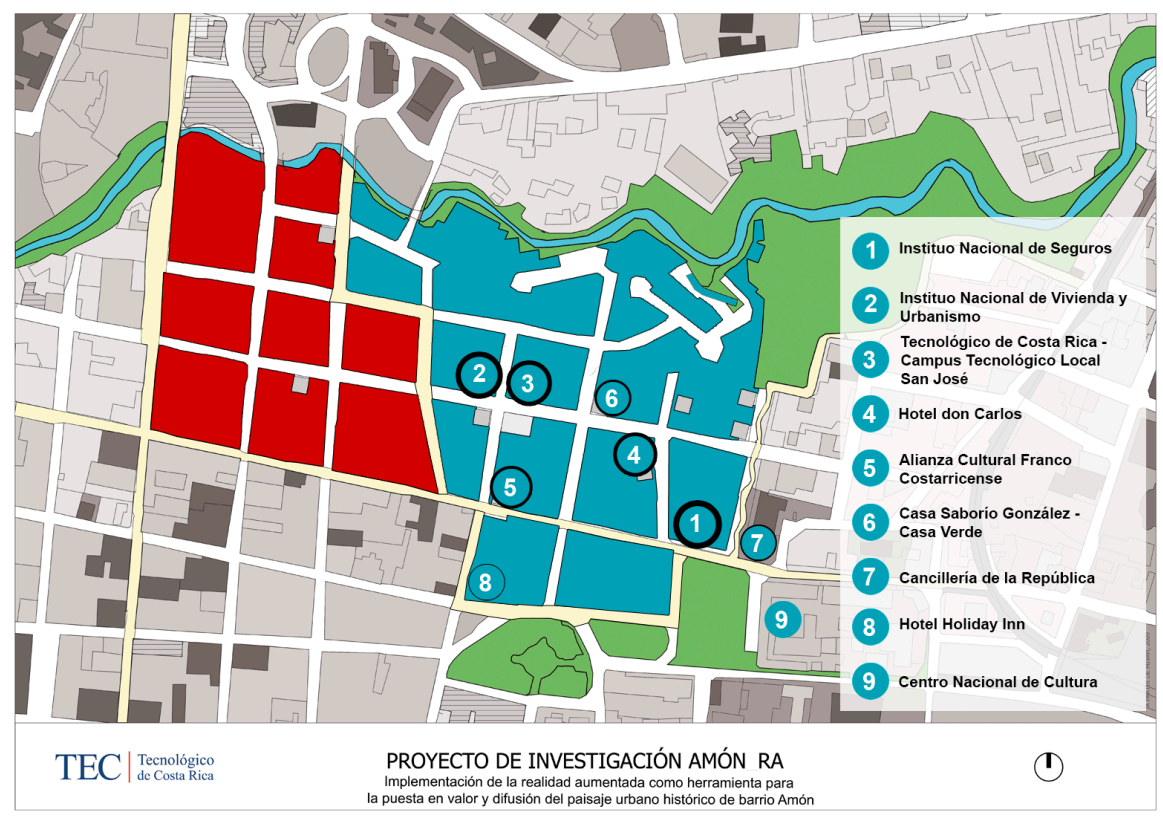

Imagen 16: plano de hitos de barrio Amón. Los principales puntos de referencia del barrio son aquellos edificios pertenecientes a instituciones consolidadas en el imaginario nacional, tales como el Instituto Nacional de Seguros, el Instituto Nacional de Vivienda y el Tecnológico de Costa Rica.

Fuente: Proyecto de investigación Amón_RA.

Otra característica particular de los resultados de este ejercicio fue que, cada uno de los elementos identificados como hitos son edificios esquineros o son edificios tan amplios que ocupan dos esquinas de una cuadra. El equipo de investigación no se pregunta el por qué de este fenómeno ya que no forma parte de los objetivos de la investigación, pero puede ser el punto de partida para otro tipo de estudio. Por otro lado, los últimos tres elementos seleccionados como hitos se encuentran fuera de los límites administrativos del barrio, pero forma parte de lo que el equipo de investigación ha llamado límites perceptuales. Se puede decir que los edificios de la Cancillería de la República (Casa Amarilla), el hotel Holiday Inn San José y el conjunto urbano del Centro Nacional de Cultura (CENAC), los cuales enmarcan en el imaginario colectivo a esa 
zona conocida como barrio Amón. Por último, no se concibieron como hitos las antiguas casas habitadas por expresidentes de la República, tales como Tomás Guardia Gutiérrez ${ }^{39}$, Julio Acosta García ${ }^{40}$, Otilio Ulate Blanco $^{41}$, Jose María Figueres Ferrer ${ }^{42}$ y el exdictador Jose María Tinoco Granados $^{43}$. El equipo de investigación ve necesario que los futuros usuarios de la aplicación móvil conozcan estos y otros datos propios de la capa histórica del PUHBA, con el fin que se valorice la importancia del barrio dentro de la construcción de la identidad nacional costarricense; por lo que la ubicación de estas viviendas, como la geolocalización de hechos históricos que acontecieron dentro del barrio, serán parte de las herramientas incorporadas dentro de Amón_RA.

39. El expresidente Tomás Guardia Gutiérrez habitó la casa que actualmente es conocida como Hotel don Carlos, si bien este edificio se fue identificado como hito, ninguno de los participantes lo asoció con el expresidente.

40. La vivienda del expresidente Julio Acosta García estuvo ubicada en avenida 9, entre calle 7 y 9.

41. La residencia del expresidente Utilio Ulate Blanco se ubica en calle 1, entre avenida 7 y 9.

42. El expresidente Jose María Figueres Ferrer habitó lo que hoy es conocido como Centro Costarricense de Producción Cinematográfica o Centro de Cine, en dicha residencia se efectuaron varias reuniones de la Junta Constituyente de 1949.

43. El exdictador Jose María Tinoco Granados habitó la vivienda ubicada entre avenida 9 y calle 3. 


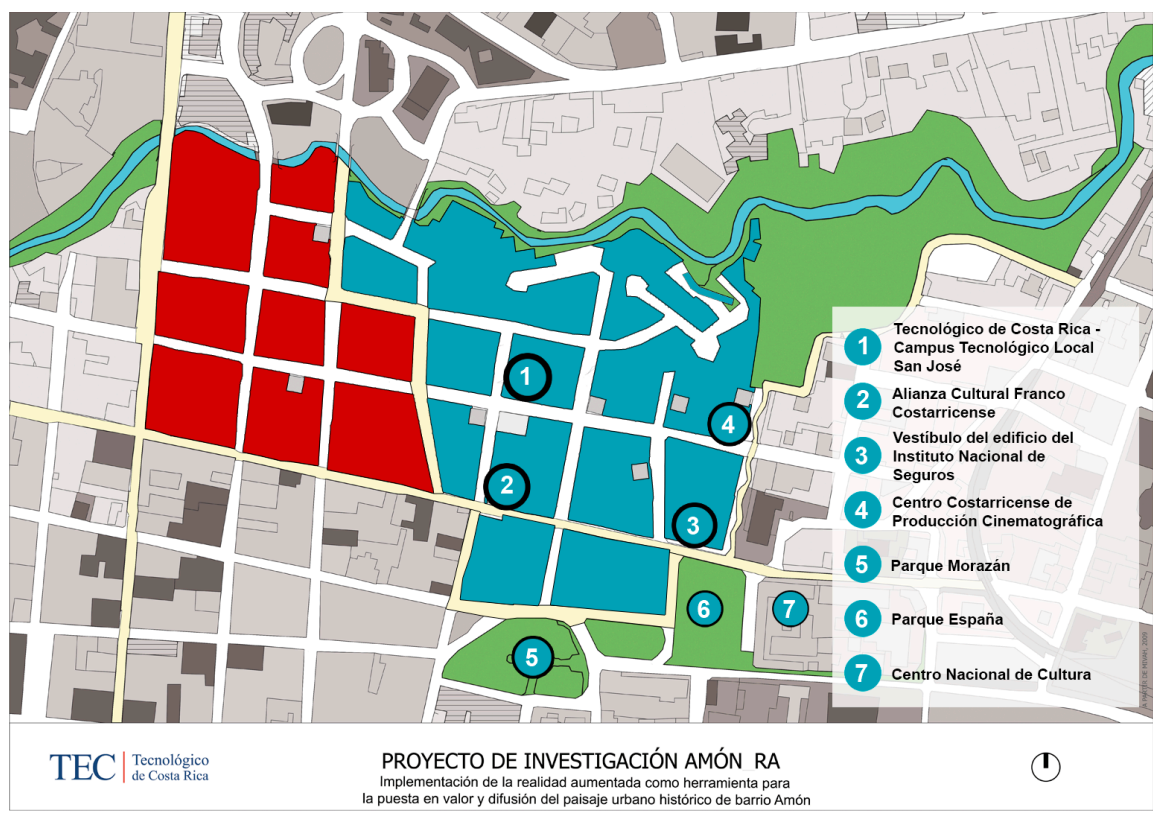

Imagen 17: plano de Nodos de barrio Amón. Los puntos de encuentro relevantes del barrio son tanto los edificios pertenecientes a instituciones públicas o privadas como los espacios urbanos verdes cercanos a los límites administrativos del barrio.

Fuente: Proyecto de investigación Amón_RA.

En la Imagen 17 se señalan los nodos del barrio o puntos estratégicos del barrio, a los que el peatón puede ingresar y que constituyen focos de encuentro de los que se emprende hacia un destino definido. Al igual que los hitos, se consideran como nodos aquellos elementos significativos que fueron mencionados por los participantes. Los primeros cuatro puntos identificados como nodos son edificios con carácter institucional, siendo la Alianza Francesa el único ente privado, y que se encuentran dentro de los límites administrativos del barrio; se puede decir que enmarcan el núcleo del barrio. Los últimos tres nodos son los parques ubicados al sur del barrio y el CENAC, estos fuera de los límites administrativos, pero conteniendo los límites perceptuales. Para varios vecinos y visitantes, este conjunto urbano forma parte de Amón, 
pues muchas de las actividades sociales ${ }^{44}$ del barrio ocurrieron ahí debido a su cercanía; además, se reafirma actualmente con actividades culturales como el Festival de Verano Transitarte ${ }^{45}$, que se ejecuta precisamente en esos espacios y donde muchos de sus participantes visitan el barrio, aprovechando su oferta gastronómica y cultural. Estos nodos servirán de referencia para los usuarios de la aplicación Amón_RA en la ubicación de los puntos que contengan información relevante con respecto al barrio.

\section{Taller 1}

Gracias a la actividad Ilamada "La pared del tiempo" se logró corregir impresiones en algunos hechos ocurridos en el barrio. También se identificaron eventos importantes de las décadas de 1970 hasta 2010. Eventos como los ocurridos entre las décadas de 1970 y 1980 como la construcción de los edificios que actualmente ocupan el INVU y el INS, la construcción de la Escuela Técnica Nacional, edificio que actualmente forma parte del Campus Tecnológico Local San José; o la compra de inmuebles de parte de instituciones culturales de carácter público o privado como el Centro de Cine y la Alianza Francesa, respectivamente. Estas dos décadas de transformación del barrio corresponden también a la concreción del cambio en el modelo de desarrollo del país. Además, cabe destacar que estos inmuebles son los que han sido señalados anteriormente como hitos del barrio. Por último, cabe destacar la aparición desde la década del 2010 hasta la fecha, de actividades culturales masivas como las que se han mencionado a lo largo del artículo, con el objetivo de promover la industria creativa presente en el barrio y de San José.

Sin embargo, aún existe un vacío de información oficial entre las décadas de 1950 y 1960, siendo 1963 la fecha considerada como el momento en que el barrio llegó a tener mayor densidad poblacional según el censo elaborado en ese año. Del segundo momento del taller, denominado: “Cómo es nuestro barrio?", se ligaron los eventos históricos importantes del barrio, con sus personajes y los sitios dentro del territorio en estudio. Además, fueron enlistados aquellos lugares que

\footnotetext{
44. Por ejemplo, conciertos en el llamado Templo de la Música, quiosco de estilo neoclásico ubicado en el centro del Parque Morazán.

45. Festival organizado por la Municipalidad de San José en la que, durante el segundo fin de semana de marzo, de viernes a domingo, se realizan actividades culturales, artísticas y gastronómicas en los parques Morazán, España y Nacional.
} 
para las y los participantes fueron importantes, pero que en el presente sufrieron algún cambio o desaparecieron. Algunos lugares identificados por su importancia a nivel productivo como la Cervecería Traube ${ }^{46}$ o el beneficio de café Tournón ${ }^{47}$; otros lugares por su valor histórico como la antigua casa de Juanita Mora ${ }^{48}$, o por su valor social como la antigua casa Jaime Bennett ${ }^{49}$ o el antiguo Bar Limón ${ }^{50}$. Estos y otros elementos fueron seleccionados como contenido de una sección de la aplicación móvil que el equipo de investigación denominó: "pasado perdido". Por último, se identificó todo el comercio cultural, gastronómico y turístico del barrio, logrando al final completar la base de datos de la aplicación Amón_RA.

De la actividad de comprobación de las funcionalidades ¿Cómo te imaginás Amón_RA?, los principales aportes de los potenciales usuarios consistieron en que desean que la aplicación móvil no solo sea mostrar información de los edificios, sino que esperan que se muestre información de las diferentes vivencias del barrio, como por ejemplo: los habitantes que conformaban el barrio, no solo por personajes aristocráticos; sino que se encuentran personas con empleos como: maestras, lavanderas, zapateros, entre otros. Lo anterior evidencia cómo era lo cotidiano del barrio.

Taller 2

En este segundo taller se logró obtener información más allá de la presente en los documentos o catalogada como oficial, ya que a partir de la primera actividad "Afiche anecdótico", se documentaron las vivencias

46. Una de las primeras cervecerías del país, ubicada en calle 0, entre avenida 11 y el río Torres.

47. Ubicado en la esquina entre avenida 13 y calle $3 \mathrm{~A}$, al lado del río Torres.

48. Hija de Juan Rafael Mora Porras, expresidente de Costa Rica y líder de la Campaña Nacional de 1856 -1857. La residencia se ubicaba en avenida 9 entre calle 0 y 1.

49. En la casa de Jaime Bennett se realizaban importantes eventos sociales del barrio, se ubicaba en la esquina entre avenida 11 y calle $3 A$.

50. Este bar era punto de encuentro de muchos vecinos del barrio y de la ciudad de San José, ubicado entre avenida 7 y calle 1, justo a la par de la vivienda del expresidente Utilio Ulate Blanco. Como anécdota se cuenta que entre el bar y la casa del expresidente existía una puerta que los comunicaba, con la demolición del bar se acabó este mito urbano. 
o anécdotas que los participantes recordaron, ligadas a los inmuebles. Algunas de las anécdotas están relacionadas con el señor Guido Sáenz González $^{51}$, familiar de los antiguos y actuales habitantes de la antigua casa González $\mathrm{Feo}^{52}$, patrimonio histórico arquitectónico de Costa Rica. Afuera de dicha vivienda, en el muro de ladrillo, se encuentran cerámicas hechas por el señor Sáenz con reproducciones ilustradas del Ingenioso Hidalgo don Quijote de la Mancha. También se mencionaron anécdotas relacionadas a juegos infantiles, como las que recordó doña Ivette Güier de cuando jugaba en el laberinto de escaleras de la casa Calvo Peña ${ }^{53}$. Esto permitió ampliar el contenido para la aplicación móvil, pero desde el ámbito de los "intangibles", presente en todo paisaje urbano histórico. Es decir, aquel contenido no material pero que se ha perdurado mediante la tradición oral en conversaciones íntimas, como los ejemplos anteriores y que, el proyecto Amón_RA ha valorado como importantes de conservar, debido a que forma parte de la identidad del barrio. Por lo tanto, ese contenido intangible ha generado secciones donde se puede encontrar información formal y anecdótica de personajes del barrio, o vivencias ligadas a las imágenes y modelos tridimensionales que los usuarios de la aplicación móvil podrán encontrar mientras la utilizan.

Con la actividad "fotos e identidad", se logró rescatar información particular del pasado y se ligó con espacios tanto urbanos como íntimos o familiares y con anécdotas de los participantes en el taller. La intención con esta información es que se transmita, por medio de la aplicación móvil, el valor intangible detrás de las herramientas de RA. Imágenes como la celebración del bautizo de doña Carmen Odio Gonzáles ${ }^{54}$, en el patio anterior a la capilla de la antigua Casa González Feo y la historia ligada a la construcción de ese inmueble, donde se rescata el fervor religioso del abuelo de doña Carmen y su intención de plasmarlo en una obra arquitectónica, con pinturas en los cielos rasos con escenas bíblicas y clásicas cuyos protagonistas tienen los rostros de

51. Creador del Ministerio de Cultura, Juventud y Deportes junto con Alberto Cañas, fundador de la Orquesta Sinfónica Juvenil, del Museo de Arte Costarricense, del Parque Metropolitano La Sabana y del Parque de la Paz.

52. Ubicada en calle 9, entre avenida 7 y 9, contiguo al Hotel don Carlos.

53. Vivienda declarada patrimonio histórico arquitectónico por la adaptación del estilo neocolonial a la tecnología constructiva del momento, se ubica al final calle 9, después de avenida 9.

54. Doña Carmen Odio González es una de las propietarias del inmueble conocido como Antigua Casa González Feo, propiedad que la adquirió su abuelo, el señor Mario González Feo, último administrador de la Fábrica Nacional de Licores cuando se encontraba al frente del Parque España. Dicha casa es reconocida por las cerámicas colocadas en el muro de ladrillo exterior, elaboradas por el señor Guido Sáenz González. 
los miembros de la familia. De la actividad del Card Sorting se obtuvo que los dos primeros grupos asociaron las tarjetas con los contenidos que el equipo de investigación había definido para la aplicación, más por la característica de similitud del contenido y del medio. Sin embargo, el tercer grupo, lo organizó más en el sentido de las posibles secciones que tendría la aplicación móvil. Siempre asociaron juntos mapas y rutas, le dieron nombre de geolocalización o mapa interactivo. Otra sección común es la parte de historia que ampliaron con personajes relacionados con las casas, así como sucesos que han pasado en el edificio y sus modificaciones. Lo anterior mostró una necesidad de suma importancia desde el punto de vista de la comunidad o vecinos, donde vieron el potencial en la aplicación como un medio para guardar a la posteridad datos anecdóticos, así como valorar el pasado perdido; es decir, aquellas edificaciones que actualmente no están, pero si tienen un registro histórico de su existencia en el barrio.

Taller 3

En las pruebas donde se brindó un tiempo para que las personas participantes pudieran conocer la aplicación móvil, ellas tuvieron mejor desempeño durante las pruebas al buscar los contenidos. Por ejemplo, en la tarea 3A: Usted desea conocer la evolución de barrio Amón a través del tiempo. ¿Dónde encontraría la información? Todos los testers lograron localizar la línea del tiempo, comentaron que se mostraba como un continuum. Lo cual es adecuado con el planteamiento original para dicho contenido, lo anterior se puede comprobar en la imagen 18. El tiempo brindado permitió a las y los participantes familiarizarse con la maqueta de la aplicación móvil e ir interactuando con los diferentes elementos y acceder al contenido. En el caso de las pruebas donde no se brindó el tiempo, permitió ver cómo los participantes trataron de ubicar contenidos por primera vez. En ambas experiencias se tuvieron dificultades similares con respecto a la asociación de ciertos contenidos con respecto al nombre de la sección. Por ejemplo; el contenido de mapas o recorridos no fueron asociados a la sección de "Viví el Paisaje". 


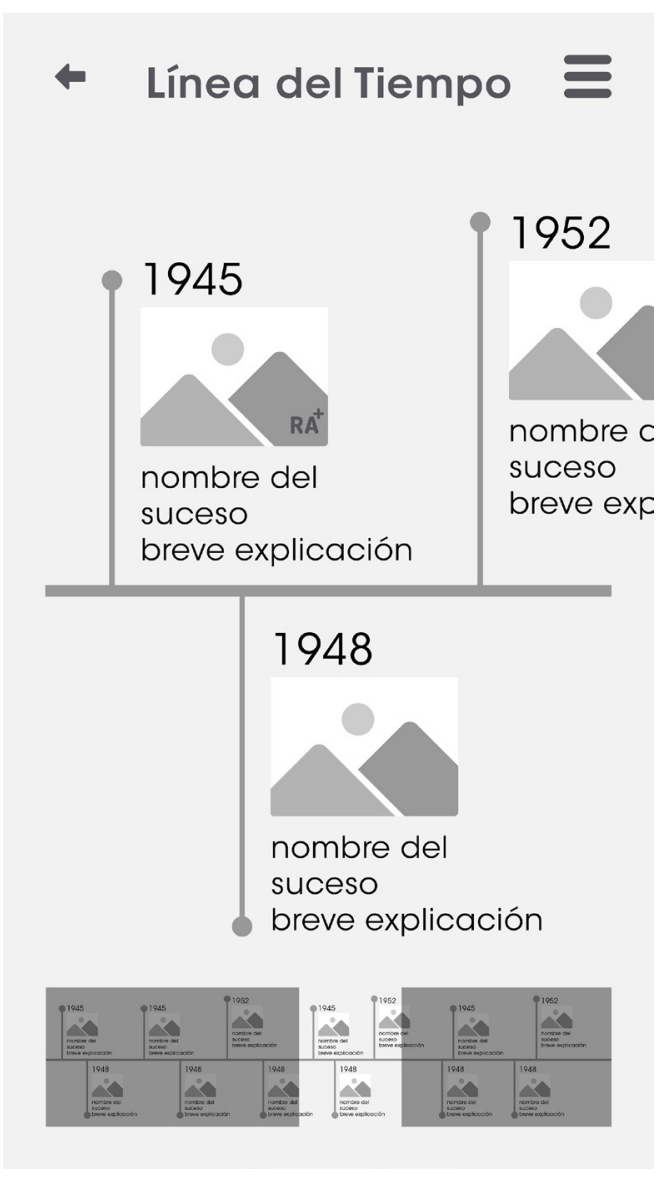

Imagen 18: La maqueta creada para el Digital Prototyping no posee color, se trabaja en grises para que el tester pueda centrarse en aspectos logísticos y no se guíe por aspectos estéticos. En la imagen se puede comprobar el reconocimiento de la línea de tiempo. Fuente: Proyecto de investigación Amón_RA.

Lo anterior es una clara evidencia que los testers no asociaron la sección con el contenido de las rutas cuando estaba bajo el nombre "Vivir la experiencia barrio Amón". En su lugar, los usuarios propusieron nombres convencionales o funcionales como, por ejemplo: Mapa interactivo. En la imagen 19 se pudo comprobar que la ubicación del mapa en la arquitectura de la información estaba en un tercer nivel. Es decir, la información del mapa con sus puntos de interés y recorridos 
deben ser accedidos de forma directa. El menú de cajón o hamburguesa funcionó bien, se puede mantener como medio general para acceder a la información de la aplicación móvil. La interfaz de galería de imágenes / botones no presentó problemas de reconocimiento o de usabilidad por parte de los participantes; además, la línea del tiempo fue bien comprendida por los usuarios.
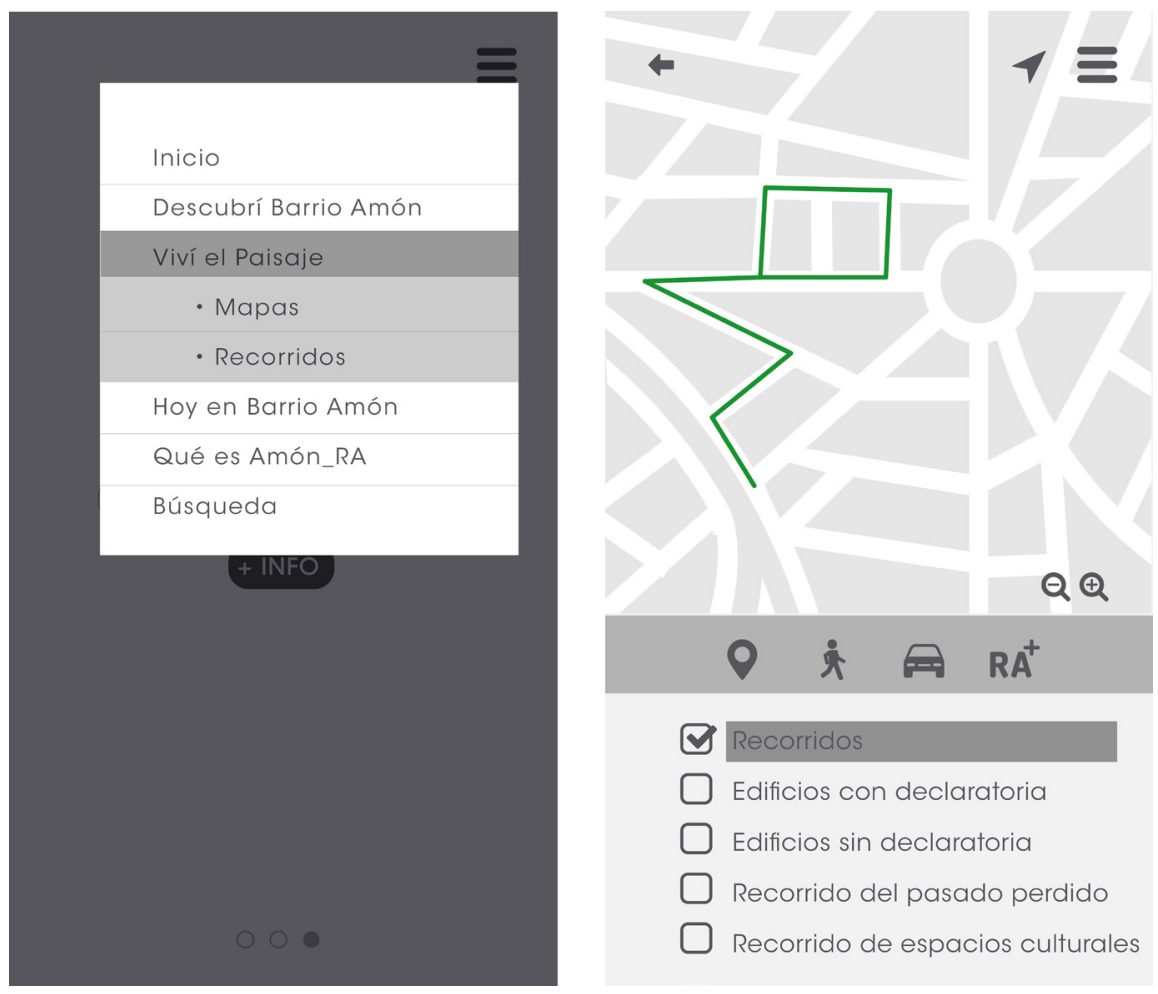

Imagen 19: Al revisar la maqueta luego de los resultados del Digital Prototyping se pudo comprobar que el acceso a las rutas estaba en un tercer nivel, como se comprueba con las pantallas arriba mostradas. Donde se tiene que acceder al menú hamburguesa para llegar a la sección Viví el Paisaje, luego se debía seleccionar mapas y por último marcar con un "check" el filtro de recorridos en el mapa.

Fuente: Proyecto de investigación Amón_RA. 


\section{CONCLUSIONES}

Si bien en los proyectos de investigación las fuentes bibliográficas son esenciales, para las aplicaciones móviles que consideren el paisaje urbano histórico como elemento primario dentro de su diseño, la información obtenida de los procesos participativos robustece el contenido, pues son los actores sociales los que transmiten de generación en generación el legado intangible.

En el imaginario de las personas que por alguna razón se encuentran en barrio Amón, los límites históricos y políticos no responden a su idea del barrio, pues estos actores no delimitan este sector de la ciudad con elementos claros; por ejemplo, parece que el límite sur del barrio es el conjunto verde que forman el parque Morazán, el parque al frente de la Escuela Buenaventura Corrales (conocido como Edificio Metálico) y el parque España. Al Sur el límite (no) natural, es decir el río Torres, no se contempla como tal, siendo sustituido por las avenidas 11 y 13; al Oeste no se define claramente un límite, pudiendo ser la Calle $3 \mathrm{~A}$ o la Calle 3 y al Este el conjunto conformado por el Zoológico y Jardín Botánico Simón Bolivar y el paseo República Argentina o calle 11 y el parque España, marca una posible división del barrio con otra parte de la ciudad.

El contar con procesos participativos durante el desarrollo de la propuesta de diseño, realimenta el proceso proyectual volviéndolo iterativo y asegurando que la aplicación móvil se adapte a las necesidades de los usuarios. La realización de pruebas con los potenciales usuarios, permitieron corroborar qué secciones de la aplicación móvil son más importantes de acuerdo con las necesidades de información y uso que podrían dar a la aplicación.

El principal aporte a nivel de la producción de conocimiento desde la investigación académica desde la disciplina de la arquitectura en general y de la arquitectura de la información en particular fue el tener accesos más directos a las secciones más valoradas, como por ejemplo las secciones de línea del tiempo, realidad aumentada, visita virtual, oferta urbana y mapa interactivo. Con estas herramientas dentro de la aplicación móvil, se le podrá presentar información de manera interactiva y geolocalizada al usuario de Amón_RA mientras esta visita el barrio, o de manera virtual si accede fuera del territorio. Tales herramientas brindan la oportunidad a quien utilice la aplicación de ampliar su

55. El menú de cajón o hamburguesa es un elemento de interacción que permite acceder a más contenidos, visualmente es un elemento que se ubica en las esquinas derecha o izquierda superior de la aplicación. Se representa con tres líneas y al realizar tap o tocar el botón despliega un menú con varias opciones, lo que permite tener una pantalla menos cargada de botones 
conocimiento natural, histórico, cultural y artístico de barrio Amón, así como información íntima de sus antiguos habitantes, permitiendo la valorización del paisaje urbano histórico en el que se encuentra. Todo lo anterior facilitaría los procesos de conservación del barrio ya que un colectivo identificaría la importancia del carácter identitario de esta zona para la ciudad de San José y para Costa Rica.

Ahora bien, la identificación de los accesos directos a las secciones ya mencionas, contribuyó a que el diseño de la aplicación móvil hiciera uso de patrones de diseño más comunes para los usuarios; por ejemplo: que se presente en primer plano el mapa interactivo y que desde este se tenga la posibilidad de acceder, mediante puntos de enlace directos, a las otras herramientas o secciones de aplicación móvil. Gracias a los procesos participativos es que el equipo investigador se propuso trabajar en las fortalezas, de Amón_RA, como la descrita anteriormente, las cuales se describen a continuación:

- Presentar toda información, ya sea gráfica o texto, con respecto a los edificios, vivencias o historia, de una manera sencilla y de fácil lectura; como por ejemplo que los textos no sobrepasen los 280 caracteres por párrafo, pero respetando la rigurosidad científica al citar la fuente del contenido; lo cual, además de facilitar la rastreabilidad de los datos, genera confianza de la veracidad de lo que se presenta. En la imagen 20 se puede comprobar cómo se visualizan los textos explicativos, cuando son accedidos por medio de la realidad aumentada.

- A partir de la necesidad de poner en valor aquellos elementos únicos presentes en el patrimonio arquitectónico del barrio, así como también de contar con espacios interactivos dentro de la aplicación móvil, es que se determinó crear un glosario arquitectónico con el que el usuario pudiese interactuar; es decir, que además de conocer por medio de palabras sencillas los componentes que aportan valor arquitectónico a una obra construida, se espera presentar dichos elementos de manera tal que el usuario pudiese ubicarlo en el edificio mediante una experiencia de RA. En la imagen 21 se muestra la forma de interacción con el glosario arquitectónico. 


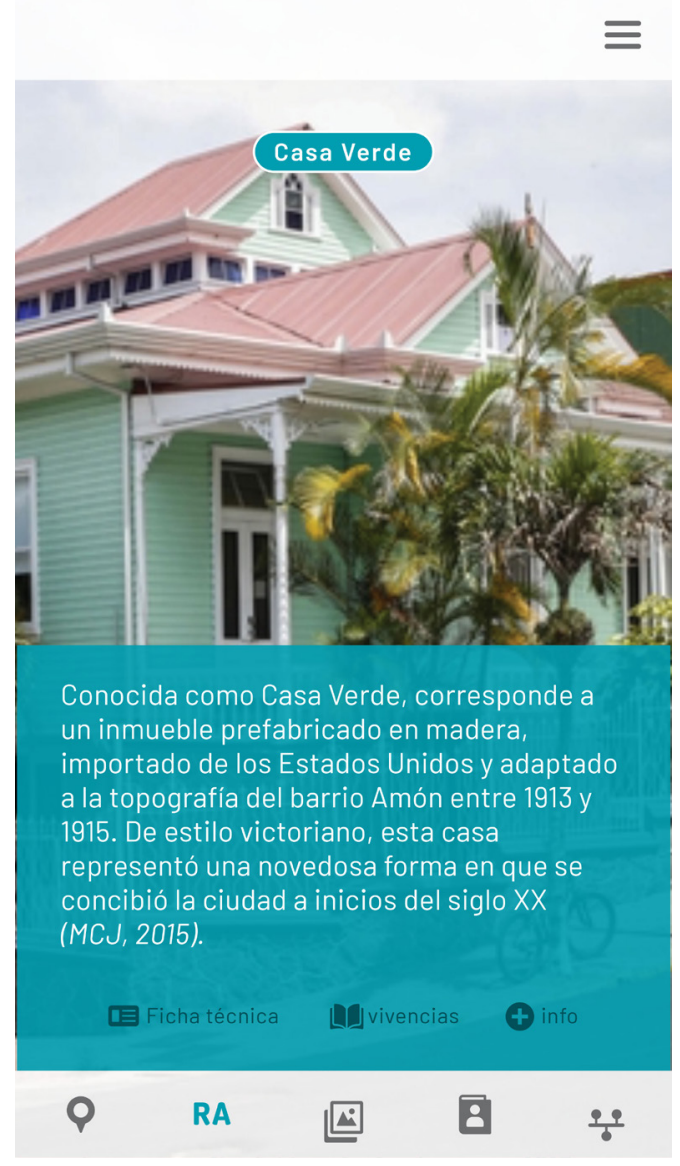

Imagen 20: En la imagen se puede apreciar cómo se mostrará la breve información de la Casa Verde, accediendo al contenido por medio de la Realidad Aumentad. Este texto no sobrepasa los 280 caracteres y le ofrece al usuario la opción de poder ampliar más el conocimiento del edificio por medio de las opciones de una ficha técnica, vivencias y otra información.

Fuente: Proyecto de investigación Amón_RA. 


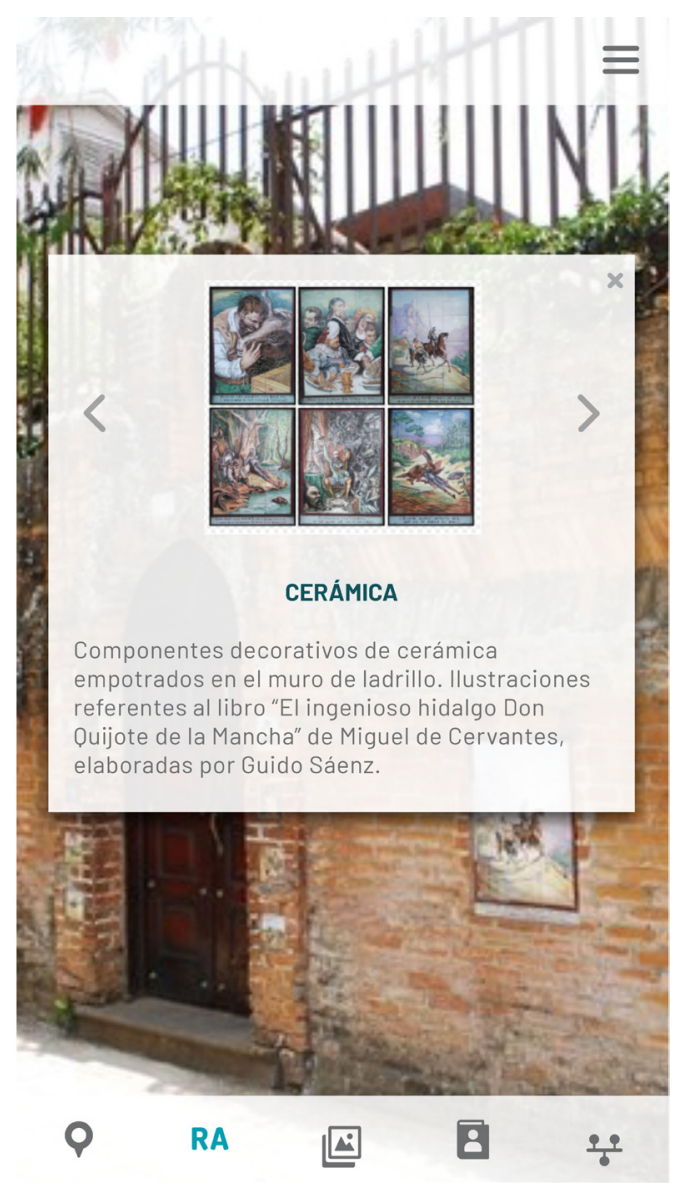

Imagen 21: El glosario arquitectónico es un medio que se le brinda al usuario para que pueda interactuar con las casas, de modo que se destacan algunos elementos presentes en la edificación y se amplía el conocimiento con un breve texto explicativo.

Fuente: Proyecto de investigación Amón_RA. 
- Develar secretos del barrio Amón, por medio del uso de fotografías 360 grados, así como por medio de la Realidad Aumentada le permite al visitante del barrio conocer aspectos de sus edificios patrimoniales que con una simple caminata por el barrio no sería accesible. Por medio de la tecnología empleada en la aplicación móvil de este proyecto y el levantamiento de relatos de las personas que vivieron algún hecho particular en esas edificaciones, fue posible gracias a los procesos de la investigación participativa y cualitativa.

- La decisión de eliminar la creación de rutas por el barrio, fue tomada con base en los hallazgos de la actividad Dibujando barrio Amón y el establecimiento de los límites del barrio. El equipo de investigadores valoró que el medio más propicio para comunicar ubicaciones e invitar a los visitantes a visitarlo es por medio del uso del mapa interactivo que claramente identifica por medio de filtros qué aspectos visitar y cómo crear su propia ruta, dependiendo del lugar en que se ubique y de los sitios de interés del usuario/a.

Las conclusiones, así como la información validada por las personas participantes en los procesos participativos, son la base para realimentar el proceso de creación de la aplicación móvil. Otros momentos posteriores del proceso de investigación consisten en la definición de los wireframes, es decir, las secciones y los contenidos que tendrá Amón_RA para pasar a la etapa de desarrollo y posterior validación con pruebas heurísticas. 


\section{BIBLIOGRAFÍA}

Calvo-Elizondo, A. (2017). Metodología Requerimientos y Diseño de Interfaces. Cartago: Escuela de Diseño Industrial, Instituto Tecnológico de Costa Rica.

Fombona, J., Pascual, M. y Madeira, M. (2012). Realidad aumentada, una evolución de las aplicaciones de los dispositivos móviles Píxel-Bit. Revista de Medios de Educación, vol. 41, pp. 197-210.

Hernández-Castro, F. (2016). Metodología para el análisis y diseño de aplicaciones (usability cookbook). Cartago: Escuela de Diseño Industrial, Instituto Tecnológico de Costa Rica.

Johnson, L., Adams-Becker, S., Gago, D., García, E. y Martín, S. (2013). NMC perspectivas tecnológicas: educación superior en América Latina 2013-2018. Un análisis regional del informe Horizon del NMC de The New Media Consortium, Austin, Texas.

Linch, K. (1998). La imagen de la ciudad. Barcelona: Gustavo Gili.

Oliva, J. \& Iso, A. (2014). Diseños metodológicos para la planificación participativa del paisaje. EMPIRIA. Revista de Metodología de Ciencias Sociales, n²7, pp. 95-120. ISSN: 1139-5737 DOI 10.5944/empiria.27.10864

Padlet (2019). ¿Qué es Padlet y su aplicación en la educación en línea? En: www.elearningmasters Recuperado de. http://elearningmasters.galileo. edu/2019/03/08/que-es-padlet-y-su-aplicacion-en-laeducacion-en-linea/

Presidencia de la República de Costa Rica y Ministerio de Cultura y Juventud. (1997). Decreto $N^{\circ}$ 26474-C: declaratoria e incorporación al patrimonio históricoarquitectónico de Costa Rica, del inmueble conocido como Alianza Cultural Franco-Costarricense. La Gaceta, №230.

Presidencia de la República de Costa Rica \& Ministerio de Cultura y Juventud. (2000). Decreto N²9042-C: declaratoria e incorporación al patrimonio históricoarquitectónico de Costa Rica, del inmueble conocido como El Castillo del Moro. La Gaceta, N²14.
Presidencia de la República de Costa Rica \& Ministerio de Cultura y Juventud. (2017). Decreto N 40662-C: declaratoria e incorporación al patrimonio históricoarquitectónico de Costa Rica, del inmueble denominado "Casa Saborío González conocido como Casa Verde". La Gaceta, N²37.

Project Management Institute (2017). La guía de los fundamentos para la dirección de proyectos, sexta edición (Guía del $\mathrm{PMBOK}^{\oplus}$ ), Chicago: Project Management Institute, Inc.

Rebollo, Ó. (2014). Bases político-metodológicas para la participación. Boletín CF+S, vol. 24. En: http://habitat. aq.upm.es/boletin/n24/

Instituto Tecnológico de Costa Rica (2019). TEC Digital. En: www.tec.ac.cr Recuperado de: https://www.tec. ac.cr/unidades/tecdigital

Tiki-Toki (2019). Líneas de tiempo interactivas con Tiki-Toki. En: https://hipertextual.com Recuperado de https://hipertextual.com/archivo/2013/07/lineas-detiempo-interactivas-con-tiki-toki/

UNESCO. (2011). Recomendación 36 C/23 sobre el paisaje urbano histórico de Actas de la Conferencia General, $36^{\circ}$ reunión, París. 